University of South Florida

DIGITAL COMMONS

@ UNIVERSITY OF SOUTH FLORIDA
Digital Commons @ University of

South Florida

$5-1-2003$

\title{
An Examination of the Relationship Between Organizational Structure and Transit Performance
}

CUTR

Follow this and additional works at: https://digitalcommons.usf.edu/cutr_nctr

\section{Scholar Commons Citation}

CUTR, "An Examination of the Relationship Between Organizational Structure and Transit Performance" (2003). Research Reports. 201.

https://digitalcommons.usf.edu/cutr_nctr/201

This Technical Report is brought to you for free and open access by the National Center for Transit Research (NCTR) Archive (2000-2020) at Digital Commons @ University of South Florida. It has been accepted for inclusion in Research Reports by an authorized administrator of Digital Commons @ University of South Florida. For more information, please contact digitalcommons@usf.edu. 


\section{ANEXAMINATION OF THE RELATIONSHIP BETWEEN ORGANIZATIONAL STRUCTURE AND TRANSIT PERFORMANCE}

May 2003

Final Report
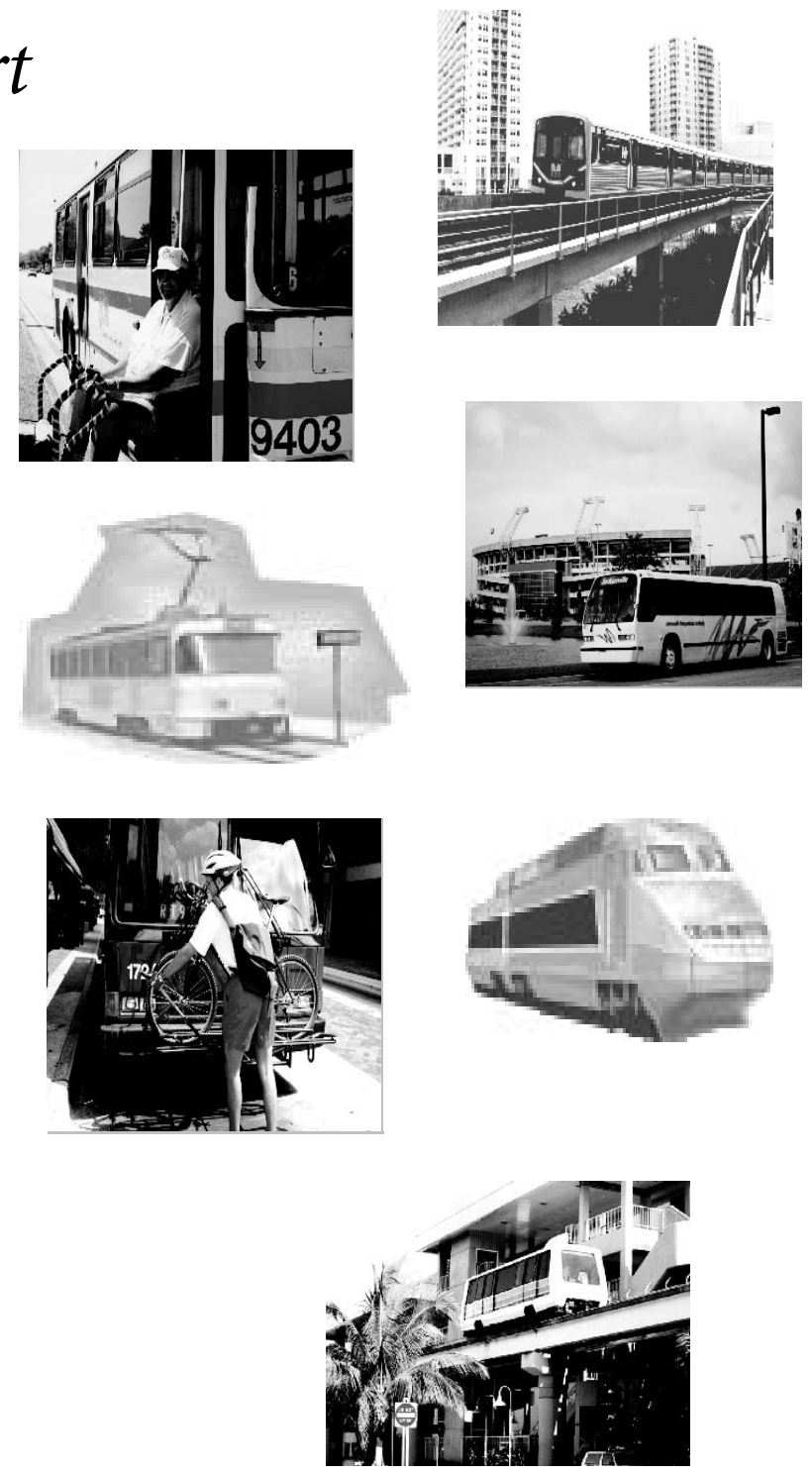
TECHNICAL REPORT STANDARD TITLE PAGE

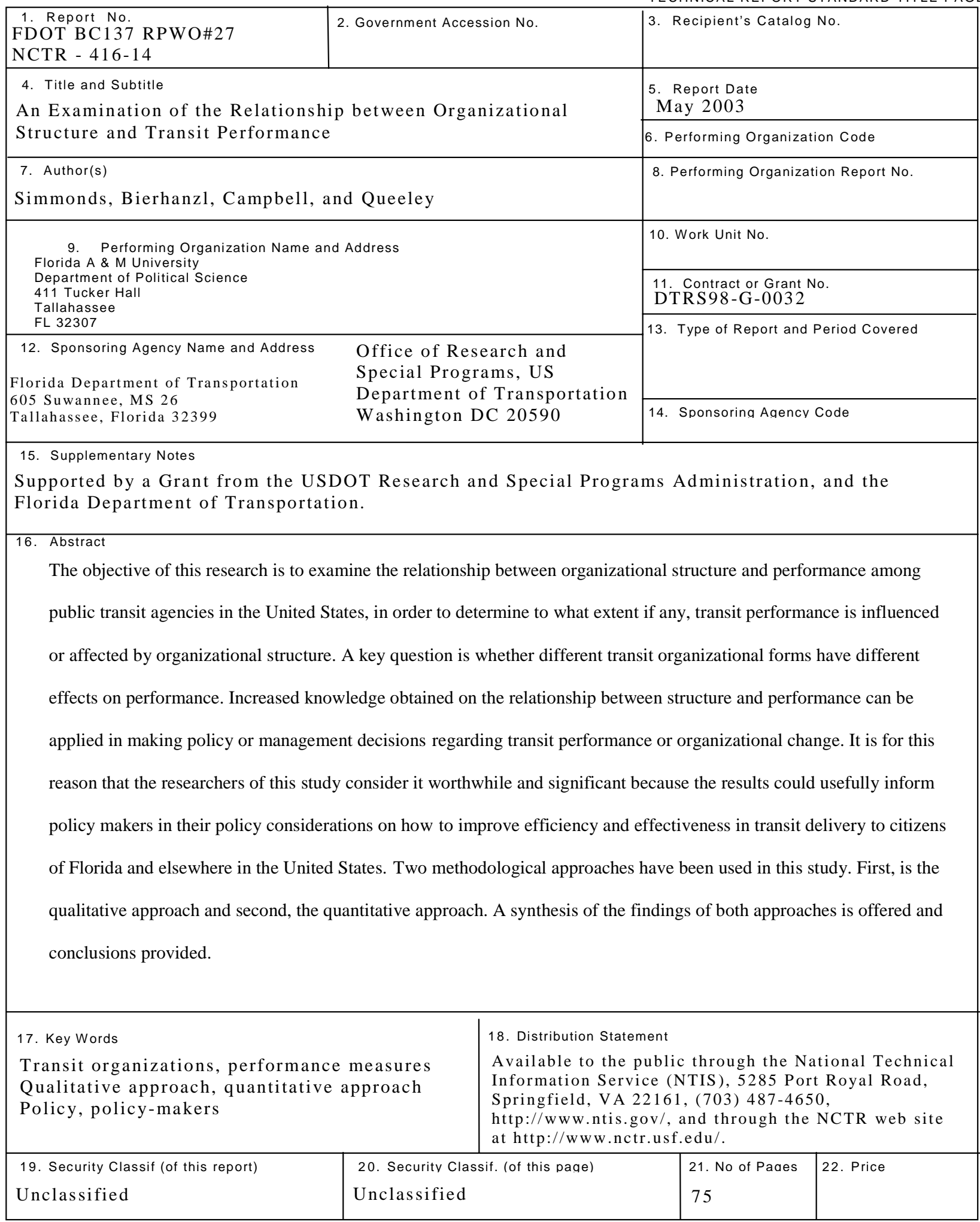

Form DOT F 1700.7 (8-69) 


\title{
An Examination of the Relationship Between Organizational Structure and Transit Performance
}

\author{
Prepared by \\ Keith C. Simmonds, Ph.D., Principal Investigator \\ Edward Bierhanzl, Ph.D., Research Associate \\ Michael Campbell, Ph.D., Research Associate \\ Gilbert Queeley, Research Associate \\ Florida A \& M University \\ Tallahassee, FL 32307 \\ 850.561 .2837 \\ Prepared for \\ National Center for Transit Research (NCTR) \\ Center for Urban Transportation Research \\ University of South Florida, Tampa \\ Project Manager \\ Ike Ubaka, FDOT \\ Contract Number BC 137-27 \\ Florida Department of Transportation \\ 605 Suwannee Street \\ Tallahassee, Florida 32399-0450 \\ Research and Special Program Administration \\ U.S. Department of Transportation \\ RSPA/DIR-1, Room 8417 \\ 4007 th Street, SW \\ Washington, DC 20590 \\ http://www.rspa.dot.gov/
}

The opinions, findings, and recommendations expressed in this publication are those of the authors and not necessarily those of the Florida Department of Transportation of the U.S. Department of Transportation.

The document was prepared in cooperation with the State of Florida Department of Transportation and the U.S. Department of Transportation 


\section{Table of Contents}

Executive Summary

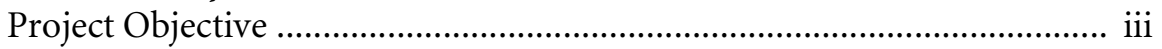

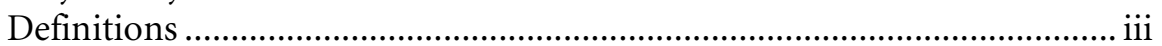

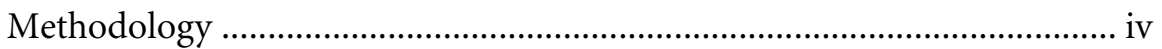

Quantitative Methodology and Analysis ................................................... vi

Summary and Conclusion........................................................................ viii

Part 1. Introduction

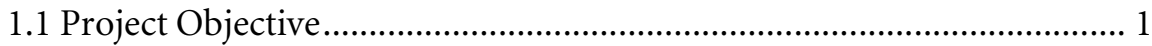

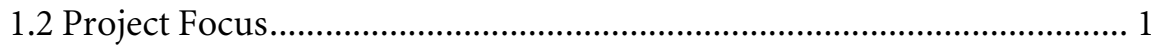

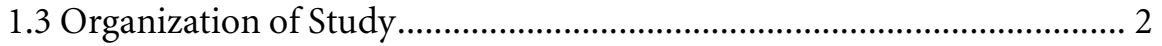

Part 2. Literature Review

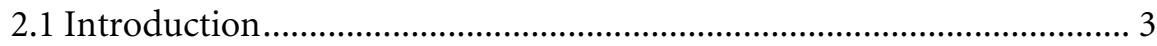

2.2 Economic, Business and Public Admin. Perspectives: A Synthesis ........ 3

2.3 Management structures ........................................................................ 4

2.4 Transit Systems: An Economic Perspective .............................................. 4

2.5 Organizational Structure: A Business Management Perspective ............. 6

2.6 Approaches to Organization Structure …………....................................... 7

2.7 The Functional Organization Structure ……............................................ 7

2.8 Geographic Organizational Structure ....................................................... 9

2.9 Decentralized Business Divisions Organizational Structure ................... 9

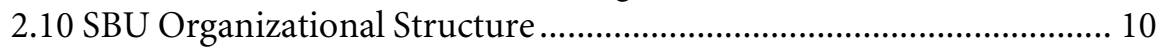

2.11 Matrix Organizational Structure ........................................................... 12

2.12 Political/Administrative Perspective on Structure ............................... 13

2.13 Identification of Transit Types With Organizational Structures ......... 16

2.14 Types of Transit Organizational Structures ....................................... 17

2.15 Contract Management........................................................................ 22

2.16 Distinction between service and management contracting................. 24

2.17 Macro vs. Micro Level Structure …………........................................... 27

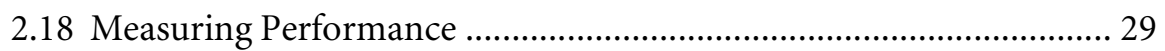

2.19 Consensus on Measuring Transit Performance..................................... 33

Part 3. Methodology, Analysis and Findings

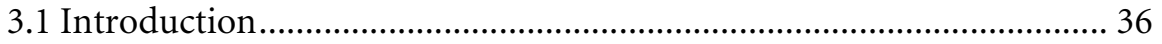

3.2 Focus and Approach........................................................................... 36

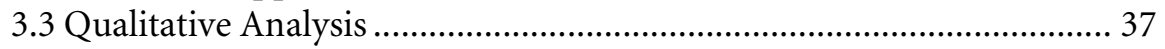

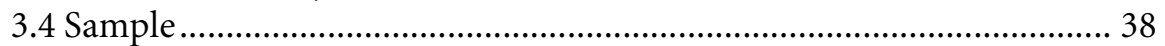

3.5 Results and Discussion ........................................................................ 38

3.6 Conclusions From the Survey on Qualitative Factors Affecting

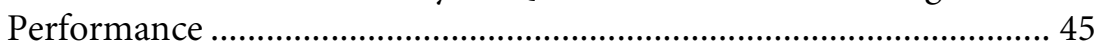




\section{List of Tables \& Figures}

Part 4. Quantitative Analysis And Findings

4.1 Introduction 47

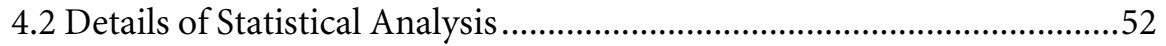

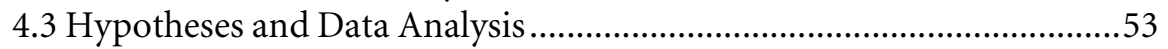

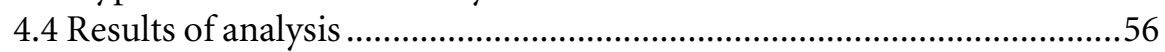

Part 5. Summary, Data Synthesis and Conclusion

5.1 Summary.....

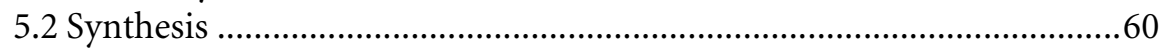

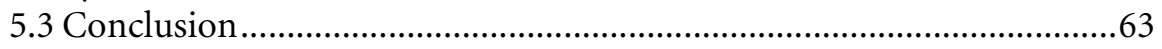

Appendix 1: List of Transit Agencies Included in Sample ...................................66

Appendix 2: Transportation Structure and Performance Questionnaire .............73

\section{List of Tables \& Figures}

Table 1: Florida Transit Agency Organizational Structures

Table 2: Sample List of National Transit Agencies According to Organizational Structure

Table 3: Distribution of managers with respect to years of experience................39

Table 4: Distribution of agencies with respect to govt. interaction .......................40

Table 5: Distribution of agencies by type …………........................................40

Table 6: Distribution of transit managers by employment...................................41

Table 7: Managers opinion regarding quality of govt. interaction ........................41

Table 8: Mangers opinion on transit guidelines that effect performance ............42

Table 9: Mangers opinion on transit guidelines that hinder performance .........42

Table 10: Mangers opinion on rules \& guidelines that govern the industry .........43

Table 11: Mangers opinion with respect to changes in decision rules \& guidelines43

Table 12: Distribution of agencies with respect to the frequency of training for their staff.

Table 13: Distribution of agencies with respect to the provision of communityoriented facilities

Table 14: Breakdown of community-oriented facilities provided by transit agencies for their workers.

Table 15: Workers attitude towards the agency after the provision of community-

oriented facilities

Table 16: Effect of Type of Ownership on Performance Indicators ......................57

Table 17: Effect of Type of Management on Performance Indicators ....................58

Table 18: Joint Effects of Ownership \& Management on Performance Indicators .59

Figure 1: Satellite Model of Organization Performance. 28 


\section{Executive Summary}

PROJECT OBJECTIVE

\section{DEFINITIONS}

The objective of this research has been to examine the relationship between organizational structure and performance among public transit agencies in the United States in order to determine to what extent if any, transit performance is influenced or affected by organizational structure. A key question is whether different organizational transit forms have different effects on performance. Increased knowledge obtained on the relationship between structure and performance can be applied in making policy or management decisions regarding transit performance or organizational change. It is for this reason that the researchers of this study consider it worthwhile and significant because the results could usefully inform policy makers in their policy considerations on how to improve efficiency and effectiveness in transit delivery to citizens of Florida and elsewhere in the United States. Thus, while the focus of the study is nationwide in scope, particular attention will be paid to Florida because of the variety of organizational structures represented among Florida transit agencies.

Organizational Structure. In this study organizational structure is broadly defined as the scope and limits of behavior within an organization, its lines of authority and accountability, as well as the organization's relationship with its external environment. More specifically, and for purposes of this study structure is defined in the context of organizational form and management. That is, we have identified transit organizational structure as having four basic forms that are primarily characterized by ownership and type of management. Local governments own public transit systems in the United States but they are not all managed by their municipal or county governments. They range from being fully owned and managed by a local government to being owned by, but not managed by, a local government. The latter are generally referred to as public/private (or semi-government) management types, among which are several variations. These are properly defined as publicly owned but autonomous transit agencies. For the purpose of this study, however, we have categorized public transit systems as:

General government/public management (GGPM); i.e. agencies that are part of municipal governments (e.g. Miami-Dade Transit Agency). 
- General Government/contract management (GGCM) i.e. agencies that are part of municipal governments but contract our their management functions (e.g. Escambia County Transit in Pensacola, FL.)

$\square$ Special Authority/public management (SAPM). i.e. transit agencies that, while publicly owned are autonomous entities in the public sector (e.g. San Diego Transit Corp).

Special Authority/contract management (SACM) i.e. they are similar to SAPMs, but contract out their management functions (e.g. Ashville, North Carolina Transit Authority).

Organizational Management. By organizational management is meant leadership personnel within transit organizations. Management personnel are those who have policy formulation, determination and implementation responsibilities. They are either appointed to serve at the pleasure of elected officials or career civil servants. Their ultimate responsibility is to ensure effective and efficient delivery of transit service to citizens.

Transit Performance. This is defined in the context of ten performance measures that are commonly used in the transit industry. They are briefly identified here but discussed in sections 2 and 3 .

\section{EFFICIENCY MEASURES}

$\square$ Operating expense per revenue hour

$\square$ Total operating revenue per operating expense

$\square$ Vehicle miles per peak vehicle

Annual vehicle miles per maintenance employee

- Revenue miles between incidents

$\square$ Revenue vehicle miles per employee

\section{EFFECTIVENESS MEASURES}

$\square$ Unlinked passenger trips per revenue hour

Unlinked passenger trips per operating expenses

Unlinked passenger trips per capita

U Unlinked passenger trips per revenue vehicle mile

\section{METHODOLOGY}

Rationale. Two methodological approaches have been used in this study. First, is the qualitative approach and second, the quantitative approach. 
The qualitative approach was utilized because of the non-quantifiable aspects of management and organizational structure that exist. We are well aware of the fact that, for example, one cannot easily quantify the contributions of years of service in management, or how much more contribution to performance will result from management's successful efforts at increasing workers' satisfaction. Yet it was important to gauge the extent to which these micro-management elements of transit structures are important in the study of the relationship between structure and performance. These findings (please see qualitative analysis section of study) add validity to the quantitative results, which are discussed in the latter part of section 3. Also, we believe that a better understanding of these micro-structural features could inform public policy making in the transit industry as to how to improve performance in areas deserving of improvement, and where appropriate, could be used to recommend change in existing structural relationships.

\section{FINDINGS OF QUALITATIVE STUDY}

1. Experienced managers currently manage public transit agencies; though we could not quantify the precise contribution of managerial experience to performance, yet such an element of management is broadly believed by transit managers to contribute to transit performance.

2. Most respondents, however, feel that more important than managerial experience to improving transit performance is funding. Additionally, because of the critical importance of funding to transit agencies, most managers expressed a strong desire to obtain greater flexibility in mandated fiscal guidelines that govern the use of funds from all levels of government. This recognition of the importance of funding was further expressed when a majority of transit managers communicated the view that their agencies are "budget recipients of last resort and, therefore, experience minimal efficiency in operations and service delivery." By implication, this is an indirect way of acknowledging the positive influence that intergovernmental funding has on transit performance among transit agencies.

3. According to respondents to our questionnaire, there are other factors that could enhance performance. These imply the consumer-oriented approach to public transit service delivery particularly with regard to employees who are directly involved in service delivery at the operational levels of bus drivers, maintenance, etc., Examples of these factors include the provision of community-oriented facilities such as health care and day-care centers for employees. A majority of 


\section{Executive Summary}

the managers whose agencies provided these benefits indicated that they have seen an improvement in attitudes toward their agency. Continuing research has shown that satisfied workers tend to be more productive. Performance could therefore be improved through the provision of training, health care benefits and/or facilities, and other benefits to workers.

In sum, these findings indicate that a study of the effect of structure on performance goes beyond structural forms (e.g. general government v. special authority) but that there are micro-structural variables that ought to be recognized for their impact on performance.

QUANTITATIVE METHODOLOGY AND ANALYSIS
The three key variables employed in the quantitative model are structure, organization and performance. Traditionally, transit structures are categorized on the basis of type of ownership and type of management. When management is defined in terms of personnel not related to ownership, it is necessary (sometimes because of policy implications) to determine whether different forms of management have significant effects on transit performance. Evaluating management as a component of structure is important since this allows researchers to more carefully examine the performance effects due to management and not confuse them with effects due to ownership. Using quantitative analysis of available transit data we were able to empirically demonstrate this. This study tested the effects of ownership, management and ownership-management combinations on transit agency performance.

Presenting organizational structure and organizational management in this way, allowed us to test three separate hypotheses:

1.After controlling for demographic and other variables, agencies that are part of municipal governments do not perform significantly better compared to special authorities. That is: $\mu_{1}=\mu_{2}$

Where: $\mu_{1}=$ the mean for a specific performance measure observed for agencies that are part of municipal governments and $\mu_{2}=$ the mean for a specific performance measure for special or independent authorities.

2.After controlling for demographic and other variables, agencies that are part of municipalities do not perform significantly better compared to contract-managed agencies. That is: $\mu_{3}=\mu_{4}$

Where: $\mu_{3}=$ the mean for a specific performance measure observed for agencies that are part of municipal governments and $\mu_{4}=$ the mean for a specific performance measure for contract managed agencies. 


\section{Executive Summary}

3.After controlling for demographic and other variables, there will be no significant difference in performance between the four ownershipmanagement combinations that define the transit agency structures covered in the literature.

That is: $\mu_{1}=\mu_{2}=\mu_{3}=\mu_{4}$

Drawing from the different forms of transit ownership and management outlined in the literature review, four general forms of ownership-management combinations (structures) were made possible. These have already been referred to as:

General Government/Publicly Managed (GGPM); General Government/Contract Managed (GGCM);Special Authority/Publicly Managed (SAPM);Special Authority/Contract Managed (SACM)

In this case then, the third hypothesis tested was:

In conceptual form, a model depicting the dependency of performance on structure can be expressed as follows:

$$
\mathrm{PER}_{\mathrm{it}}=\mathrm{f}(\alpha, \phi, \alpha \phi) \quad(\text { Equation } 1)
$$

Where:

$\mathrm{PER}_{\mathrm{It}}=$ The performance observed for the the $\mathrm{i}^{\text {th }}$ performance measure in time period $t(t=$ the year 2000$)$ and ( $i=$ performance measures 1 to 10 )

$\alpha=$ Agencies that conform to a particular type of ownership ( $\alpha=1$ to 2 ) i.e. agencies that are part of municipal governments or special authority.

$\phi=$ Agencies that conform to a particular type of management ( $\phi=1$ to 2 ) i.e. agencies that are part of municipal governments or contract management.

$\alpha \phi=$ A specific ownership-management combination that defines a particular transit agency structure. ( $\alpha \phi=1$ to 4$)$ i.e. GGPM, GGCM, SAPM and SACM

With the conceptual model provided in equation 1 , it is possible to estimate the individual (main) effects of ownership and management as well as, their joint (interaction) effects without confounding their relative contributions to performance. As such, the empirical model used to estimate 
the effects of ownership, management and ownership-management combinations, was specified as follows:

$$
\mathrm{PER}_{\mathrm{it}}=\beta+\alpha_{\mathrm{i}}+\phi_{\mathrm{j}}+\alpha_{\mathrm{i}} \phi_{\mathrm{j}}+\mathrm{E}_{\mathrm{ij}}(\text { Equation 2) }
$$

Where:

$\mathrm{PER}_{\mathrm{it}}=$ the performance value observed for the $\mathrm{i}^{\text {th }}$ performance measure in time period $\mathrm{t},(\mathrm{t}=$ the year 2000) and $(\mathrm{i}=$ performance measures1 to 10).

$\beta=A$ common effect for the overall experiment which is an unknown constant.

$\alpha_{i}=$ The mean performance value observed for the $\mathrm{i}^{\text {th }}$ type of ownership ( $\mathrm{i}$ $=1$ to 2 )

$\phi_{j}=$ The mean performance value observed for the $\mathrm{j}^{\text {th }}$ form of management ( $\mathrm{j}=1$ to 2$)$

$\alpha \phi_{\mathrm{ij}}=$ An effect due to a specific ownership-management combination (ij $=4$ )

and

SUMMARY AND CONCLUSION
The results of this methodological approach led to the following findings which are preceded with a brief summary statement:

Good management continually searches for increased efficiencies, that is, increased output per unit, at lower costs. Contract management or out-sourcing is still commonly adopted and implemented in the public sector. This study, however, has not found any significant difference between publicly managed transit agencies and contract management agencies. Indeed, for transit policy makers who wish to opt for increased contract management our research could not support that decision. 


\section{Executive Summary}

Policy makers, however, can be informed by the following specific findings of our study:

Special (Independent) authorities perform better compared to agencies that are part of municipal governments. Our results show that these structures had a higher mean performance in 8 of 10 indicators.

- Statistically, however, there was no significant difference in performance where type of ownership was concerned.

$\square$ Agencies that are part of municipal governments proved to be more efficient compared to contract management agencies. They had a higher mean performance in 7 of 10 indicators.

$\square$ Contract management agencies, however, had a higher effectiveness mean performance than agencies that are part of municipal governments.

None of the four (4) structures we studied (GGPM, GGCM, SAPM, SACM) displayed any significant difference in performance. That is, statistically, none of the structures studied can be said to be superior in performance when compared to the others. At best we can only say that according to our findings, some structures performed better in certain performance areas than in other areas or performance activities.

It is hoped that the above summary of our qualitative and quantitative analyses would provide useful information that will serve as an important guide to transit officials and operatives in their search for better structural arrangements and improved performance in the transit industry. Clearly, more research is needed to gain more knowledge about the precise relationship between organizational structure and transit performance. It is important that future research continue to pay attention to both qualitative and quantitative approaches as the best approach to developing a better understanding of the relationship between structure and performance. Perhaps, also, follow-up or longitudinal studies will help in presenting a clearer picture regarding a core relationship in public management, that is, the relationship between structure and performance. 


\section{An Examination of the Relationship Between Organizational Structure and Transit Performance}

\section{Introduction}

\subsection{PROJECT OBJECTIVE}

\subsection{PROJECT FOCUS}

The objective of this research is to examine the relationship between organizational structure and performance among public transit agencies in the United States in order to determine to what extent if any, transit performance is influenced or affected by organizational structure. It is expected that the findings of this study would provide useful information to public transit decision makers and others who may be interested in knowing whether or not different transit organizational forms have different effects on performance. Knowledge of the relationship between structure and performance can be applied in making policy or management decisions regarding transit performance or organizational change. While the focus of the study is nationwide in scope, particular attention will be paid to Florida because of the variety of organizational structures represented among Florida transit agencies.

At a time when public transit agencies are searching for more effective and efficient ways of raising revenue, expanding ridership, increasing service miles, and also seeking ways of reducing operating costs per passenger trip and per service mile, there is a critical characteristic of bureaucratic organizations that can significantly impact public transit not only in Florida, 


\section{Section 1. Introduction}

but also nationally, as public transit agencies seek to fulfill their functional goals. This critical characteristic is organizational structure.

Organizational structure defines the scope and limits of behavior within an organization, its lines of authority and accountability, as well as the organization's relationship with its external environment. It is an important question whether policy analysts, administrators and elected officials give this public administrative matter adequate consideration in their quest for increased performance in public agencies.

This study will investigate the extent to which the organizational structure of public agencies influences these agencies' search for improvements in various measures of performance. The existing organizational structure of public agencies could be an important impediment to the maximization of goal achievement in various performance areas. The study, therefore, will investigate and evaluate the nature and extent of the relationship between organizational structure and performance in public agencies here in Florida and elsewhere in the United States.

1.3 ORGANIZATION OF STUDY
Following this introduction is a literature review (Section 2), which provides both an extensive and in-depth discussion on organizational structure and performance. Sections 3 and 4 discuss the methodology adopted for this study; section 5 discusses the results and findings of the study and section 5 offers considerations and conclusion of this research project. 


\section{Literature Review}

2.1 INTRODUCTION

2.2 ECONOMIC, BUSINESS AND PUBLIC ADMINISTRATIVE PERSPECTIVES: A SYNTHESIS
At a time when public transit agencies are searching for more effective and efficient ways of raising revenue, expanding ridership, increasing service miles, and also seeking ways of reducing operating costs per passenger trip and per service miles, there is a critical characteristic of bureaucratic organizations that can significantly impact the ability of transit agencies to achieve their functional goals. This critical characteristic is organizational structure.

Organizational structure defines the scope and limits of behavior within an organization, its lines of authority and accountability, as well as the organization's relationship with its external environment. It is an important question whether policy analysts, administrators and elected officials give this public administrative matter adequate consideration in their quest for increased performance in public agencies.

The purpose of this literature review is to provide a synthesis of economic, business and public administrative perspectives on structural factors and relationships that may influence the performance of organizations, particularly those in the public transit industry. The perspectives will serve as a background to the study's investigation as to the extent to which the organizational structure of transit agencies influences these agencies' search for improvements in various measures of performance. This study will investigate and evaluate the nature and extent of the relationship between organizational structure and performance in Florida public transit systems in particular, and in the U.S. in general. The results of this study will inform the Florida public transit policy process in its administrative considerations and legislative deliberations on improving public transit performance in Florida.

Perhaps the most important element in the analysis of the relationship between organizational structure and performance is the distinction between publicly and privately managed transit agencies. This distinction is important for two reasons: it highlights the different performance measures that are appropriate for each category and it emphasizes the different incentives that are present under the two structures.

The notion of what constitutes "performance" is distinctly different for a private, for-profit business and for a government-operated service. From this distinction flows the second significant difference between public and 


\subsection{MANAGEMENT STRUCTURES}

2.4 TRANSIT SYSTEMS: AN ECONOMIC PERSPECTIVE private management. The differences in goals and incentives that exist between public and private management are much clearer than differences that exist within each category. For this reason, there has been a great deal of attention in the economic literature to differences between public and private management.

Cervero (1984) points out that prior to the late 1950s privately owned transit systems were widespread, and it was not until later in that decade and into the 1960s that public ownership of transit systems became common. With public ownership came a growing trend in the use of public subsidies to finance expanded service in the face of falling ridership. With the switch from profit-making business to government service came changes in management priorities that often persist to this day. However, this study, while it is aware that privatized transit systems were the forerunner of public transit systems, will not address nor seek to compare the performance outputs of one over the other. It is a settled reality that public transit systems represent the present and from every indication will continue to be modus operand $i$ well into the future.

It is important, however, to establish early in this study that irrespective of the degree of "publicness" of any transit system, given the nature of the American social system, with the private sector being the beacon of hope and the standard of measurement for all interfaces, interchanges and/or exchanges of things economic or financial, even the operatives of public institutions or systems, will continue to measure their performance in the scales of "financial and economic efficiency," which is the coin of the realm of the private sector of this or any other capitalist society. This is the background against which our study of public transit systems in the US will be placed. Background will not supersede foreground, i.e. the focus on public transit systems.

From the perspective of economic analysis, public/private distinction is fundamental. Traditionally, managerial behavior has been analyzed by assuming that firms pursue the objective of profit maximization. From this initial assumption comes a set of expectations that we have about the incentives that managers face and the way in which decisions are made. Ultimately, all the managerial decisions that take place within a firm are motivated by the goal of profit maximization. This includes decisions about the types of products or services to offer, the way in which those products are produced, the mix of inputs used in production, as well as decisions about advertising, marketing, technology adoption and so on. Incentives for efficiency, customer satisfaction, and innovation are present 
because of the competitive pressures of the market. Since the owners of firms have a residual claim on profit, they are motivated to efficiently produce goods that are valued by consumers.

\section{PUBLIC SECTOR ORGANIZATIONS}

The analysis of bureaucratic management in the public sector is quite different, however. In the public sector, there are no "owners" and so there is no residual claim for any profits that might be made by the bureau. Government bureaus are not viewed as profit maximizing entities, and even if they were, there are no incentives necessarily present for managers to operate profitably. The absence of market discipline and profit motive makes the managerial decision process in the public sector quite different from that in the private sector.

The problems created by the absence of market incentives in public-sector decision-making are compounded by the ongoing trend toward more rapid market change. Businesses continually must cope with changing market dynamics, and any inflexibility makes it difficult for businesses to be sufficiently responsive. The greater inflexibility of public sector management can be costly for transit agencies

These problems are likely to exist whether the agency under consideration is a part of a larger governmental unit or whether it is a quasi-independent "public authority". It is important to recognize these similarities, since public authorities have become an increasingly popular way for municipal governments to provide services. These authorities are commonly found providing water supply, sewer service, and fire protection, as well as various transportation-related services. While they are unlike municipal governments in that they exist for one specific purpose, they still retain the governmental authority that makes them quite distinct from private sector firms. The possible complications that this can create are detailed in Gillette (1994).

In fact, it has only been in the last few decades that economic analysis has been systematically applied to public sector activity. The discipline of public choice in economics deals with the analysis of decision-making in the public sector. One of the most basic areas of public choice analysis involves an examination of the differences between private and public management and the implications that those differences have for outcomes in the public sector. 
A straightforward example of this in municipal finance would be a direct comparison of similar services provided by a local government and a private company. Parking services can easily be compared in this way, as both public and private parking provision often coexists in cities. Furthermore, parking is a service that is easily quantifiable (in terms of space size, ease of entry and exit, and convenience to destination) and therefore is easily compared across providers. Similarly, parks or recreation facilities such as golf courses can be compared in the same way. In his 1989 book, Dennis Mueller published evidence collected from some fifty such studies, and demonstrated that in the majority of cases, private provision is more efficient than public provision.

In these studies it is common for efficiency to be defined as producing a particular level of service in the least costly way, and so it is not surprising to find this result. Private firms that face competition and market pressures tend to produce products at a lower cost when compared with public agencies that do not face similar pressure. While studies such as these can dramatically illustrate the difference between public and private management structures they are difficult to apply directly to transit services. This difficulty stems from the general absence of private firms providing transportation services that are directly comparable to the services provided by municipalities.

2.5 ORGANIZATIONAL STRUCTURE: A BUSINESS MANAGEMENT PERSPECTIVE
It is important to note that the public/private dichotomy is not the only approach to determining the relationship between structure and performance. Indeed, there are many dimensions to organizational structure, but recent developments in the transit industry have focused on management. In a discussion on the emerging new paradigms in the transit industry, a report from the Transportation Cooperative Research Program (TCRP) focuses on changes that business and industry must face. Among these, there is an emphasis on management restructuring, decentralization, and an expanded focus on service, value, and customers. A similar emphasis on decentralization and flexibility can be found in recent management literature as well, and the following discussion highlights the current concepts and perspectives on organizational structure.

\section{DEFINITION OF STRUCTURE}

Organizational theorists have defined structure as the configuration of relationships with respect to the allocation of tasks, responsibilities, and authority (Greenberg \& Baron, 1997; Jones, 1995; Stewart \& Barrick, 2000). Organizational structure institutionalizes how people interact with 
each other, how communication flows, and how power relationships are defined. The structure of an organization reflects the value-based choices made by the company (Zarnmuto \& O'Connor, 1992); it refers to how tasks are formally divided, grouped, and coordinated. Quinn's (1988) competing values model shows how different value orientations of organizations can influence structure.

One dimension of value systems that is related to structure is the controlflexibility dimension (Quinn, 1988; Zammuto and Krakower, 1991). Control-oriented value systems try to consolidate management control by centralizing decision making in managerial hands and decreasing employee discretion and flexibility. This results in a highly mechanistic structure that emphasizes the importance of achieving high levels of production and efficiency through the use of formal procedures, centralized authority, direct supervision, and specialized labor. In such companies and other similar type agencies, coordination and problem-resolution occur at high levels of the hierarchy. Employees are unlikely to recognize problems as they occur due to their limited understanding of the overall process. Even when employees recognize problems, they do not have the authority to correct them without management approval (Liu et al., 1990). Organizational control processes are hierarchical (Barker, 1993) and involve vertical coordination and communication, and vertical dependency.

To reinforce the above discussion on organizational structure it is useful to point out the broad dimensions of the structure of organizations.

2.6 APPROACHES TO ORGANIZATION STRUCTURE

2.7 THE FUNCTIONAL ORGANIZATION STRUCTURE
There are essentially five strategy-related approaches to organization: (1) functional specialization, (2) geographic organization, (3) decentralized business divisions, (4) strategic business units, and (5) matrix structures featuring dual lines of authority and strategic priority. Each form relates structure to strategy in a unique way and, consequently, has its own set of strategy-related advantages and disadvantages.

A functional organization structure tends to be effective in single-business units where key activities revolve around well defined skills and areas of specialization. In such cases, in-depth specialization and focused concentration on performing functional area tasks and activities can enhance both operating efficiency and the development of a distinctive competence. Generally speaking, organizing by functional specialties promotes full utilization of the most up-to-date technical skills and helps a business, whether private or public, capitalize on the efficiency gains resulting from use of those technical skills; it also helps a business capitalize on the effi- 


\section{Section 2. Literature Review}

ciency gains resulting from the use of specialized manpower, facilities, and equipment. These are strategically important considerations for singlebusiness organizations, dominant product enterprises, and vertically integrated firms, and account for why they usually have some kind of centralized, functionally specialized structure. This type of organizational structure is commonly used by privately owned public transit companies.

The following are strategic strengths and weaknesses associated with the functional organizational structure:

\section{STRATEGIC STRENGTHS}

$\square$ Permits centralized control of strategic results.

- Very well suited for structuring a single business.

$\square$ Structure is linked tightly to strategy by designating key activities as functional units.

$\square$ Promotes in-depth functional expertise.

$\square$ Well suited to developing a functional-based distinctive competence.

$\square$ Conducive to exploiting learning/experience curve effects associated with functional specialization.

$\square$ Enhances operating efficiency where tasks are routine and repetitive.

\section{STRATEGIC WEAKNESSES}

$\square$ Poses problems of functional coordination.

Can lead to interfunctional rivalry, conflict, and empire building.

$\square$ May promote overspecialization and narrow management viewpoints.

Hinders development of managers with cross-functional experience because the ladder of advancement is up the ranks within the same functional area.

Forces profit responsibility to the top of the organization.

Functional specialists often attach more importance to what's best for the functional area than to what's best for the whole business.

- May lead to uneconomically small units or underutilization of specialized facilities and manpower.

- Functional myopia often works against creative entrepreneurship, adapting to change, and attempts to restructure the activity-cost chain. 


\subsection{GEOGRAPHIC ORGANIZATIONAL STRUCTURE}

Organizing according to geographic areas or territories is a rather common structural form for large-scale enterprises whose strategies need to be tailored to fit the particular needs and features of different geographical areas. Geographic organizational structures have its advantages and disadvantages, but the chief reason for its popularity is that it promotes improved performance. In the private sector, chain store retailers, power companies, cement firms, and dairy products enterprises typically utilize a geographic structure. In the public sector, such organizations as the Internal Revenue Service, the Social Security Administration, the federal courts, the U.S. Postal Service, the state troopers, and the Red Cross have adopted geographic structures in order to be directly accessible to geographically dispersed clienteles (Strickland, 1987). Further discussion with regard to advantages and disadvantages would be outside the scope of this literature review since such types are not typically associated with transit systems.

Grouping activities along business and product lines has been a clear-cut trend among diversified enterprises for the past eight decades, beginning with the pioneering efforts of DuPont and General Motors in the 1920s. Separate business/product divisions emerged because diversification made a functionally specialized manager's job incredibly complex. Grouping key activities belonging to the same business under one organizational roof, thereby creating line-of-business divisions, facilitates strategy implementation. The outcome is not only a structure that fits strategy but also a structure that makes the jobs of managers more doable.

Most publicly owned and operated public transit companies utilize this organizational structure. Public transit is a division attached to the larger city or county government operations. Advantages and disadvantages particularly viewed from a general business perspective are cited as follows.

The following are strategic strengths and weaknesses associated with the decentralized business divisions organizational structure:

\section{STRATEGIC STRENGTHS}

- Offers a logical and workable means of decentralizing responsibility and delegating authority in diversified organizations.

- Puts responsibility for business strategy in closer proximity to each business's unique environment.

Allows each business unit to organize around its own set of key activities and functional area requirements. 
- Frees CEO to handle corporate strategy issues.

- Puts clear profit/loss accountability on shoulders of business unit managers.

\section{STRATEGIC WEAKNESSES}

May lead to costly duplication of staff functions at corporate and business unit levels, thus raising administrative overhead costs.

$\square$ Poses a problem of what decisions to centralize and what decisions to decentralize (business managers need enough authority to get the job done, but not so much that corporate management loses control of key business level decisions).

$\square$ May lead to excessive division rivalry for corporate resources and attention.

- Business/division autonomy works against achieving coordination of related activities in different business units, thus blocking to some extent the capture of strategic fit benefits.

$\square$ Corporate management becomes heavily dependent on business unit managers.

- Corporate managers can lose touch with business unit situations, end up surprised when problems arise, and not know much about how to fix such problems.

2.10 SBU ORGANIZATIONAL STRUCTURE
A strategic business unit (SBU) is a grouping of business units based on some important strategic elements common to each; the possible elements of relatedness include an overlapping set of competitors, a closely related strategic mission, a common need to compete globally, an ability to accomplish integrated strategic planning, common key success factors, and technologically related growth opportunities. In large, diversified companies, the number of decentralized business units can be so great that the span of control is too much for a single chief executive. Then it may be useful to group those that are related and to delegate authority over them to a senior executive who reports directly to the chief executive officer. While this imposes a layer of management between business-level managers and the chief executive, it may nonetheless improve strategic planning and topmanagement coordination of diverse business interests. This explains both the popularity of the group vice president concept among broadly diversified firms and the recent trend toward the formation of strategic business units (Bettis and Hall, 1983). 
Large consortium type public transit organizations adopt this form of organizational structure. Due to the diversity of services offered to the public, buses, trains and shuttles may be operated as SBUs of the larger public transit organization. Perhaps a transit system that illustrates the structure and functional operation of an SBU in the United States (and possesses similar features to that of the Denmark Transportation System model) is the San Diego Metropolitan Transit System (MTS).

San Diego MTS is governed by a 15 member board, the Metropolitan Transit Development Board (MTDB) that consists of four (4) appointed officials from the San Diego City Council, and one from each of the nine (9) surrounding cities that are a part of MTS. The San Diego County Board of Supervisors is represented by one (1) of its elected supervisors and a chairman of the board who is elected by the other members of MTDB. Its strategic business units includes San Diego Trolley, Inc. (SDTI), i.e., light rail transit operation; San Diego Transit Corporation (SDTC), i.e., a regional bus system; and San Diego and Arizona Eastern Railway Co. (SD\&AE), which is a 108 mile track and right-of-way operation.

Each agency mentioned above operates as a strategic business unit (SBU) with its independent routes, but with connecting services to the other routes. Each transit agency has an administration and operations department. Some transit agencies contract operations to private firms. MTS' successful adoption of the Strategic Business Unit organizational structure has earned for itself the reputation as one of the most innovative and successfully operated public transit systems in the United States. Additionally, MTS' success can be attributed to its decision to subscribe to the new paradigm for public transit by being innovative and increasing the quantity of its services and improving on its qualitative component by ensuring customer satisfaction. This successful combination resulted in increased ridership or consumers participation.

The following are strategic strengths and weaknesses associated with an SBU type of organizational structure:

\section{STRATEGIC STRENGTHS}

口 Provides a strategically relevant way to organize large numbers of different business units.

- Improves coordination between the role and authority of the businesses with similar strategies, markets, and growth opportunities. 
Allows strategic planning to be done at the most relevant level within the total enterprise.

$\square$ Makes the task of strategic review by top executives more objective and more effective.

Helps allocate corporate resources to areas with greatest growth opportunities.

$\square$ Promotes more cohesiveness among the new initiatives of separate but related businesses.

Facilitates the coordination of related activities within an SBU, thus helping to capture the benefits of strategic fits in the SBU.

\section{STRATEGIC WEAKNESSES}

I I is easy for the definition and grouping of businesses into SBUs to be so arbitrary that the SBU serves no purpose other than administrative convenience. If the criteria for defining SBUs are rationalizations and have little to do with the nitty-gritty of strategy coordination, then the groupings lose real strategic significance.

$\square$ The SBUs can still be myopic in charting their future direction.

Adds another layer to top management.

$\square$ The roles and authority of the CEO, the group vice president, and the business-unit manager have to be carefully worked out or the group vice president gets trapped in the middle with ill-defined authority.

Unless the SBU head is strong willed, very little strategy coordination is likely to occur across business units in the SBU.

- Performance recognition gets blurred; credit for successful business units tends to go to corporate $\mathrm{CEO}$, then to business unit head, last to group vice president.

\subsection{MATRIX ORGANIZATIONAL STRUCTURE}

A matrix organization is a structure with two (or more) channels of command, two lines of budget authority, and two sources of performance and reward. The key feature of the matrix is that product (or business) and functional lines of authority are overlaid (to form a matrix or grid), and managerial authority over the activities in each unit/cell of the matrix is shared between the product manager and functional manager. In a matrix structure, subordinates have a continuing dual assignment: to the business/product line/project and to their home base function. The outcome is a compromise between functional specialization and product line or market segment or line-of-business. A matrix-type organization is a genuinely different structural form and represents a "new way of life." One reason is 
that the unity-of-command principle is broken; two reporting channels, two bosses, and shared authority create a new kind of organizational climate. In essence, the matrix is a conflict resolution system through which strategic and operating priorities are negotiated, power is shared, and resources are allocated internally on a "strongest case for what is best overall for the unit" type basis (Galbraith, 1971).

The following are strategic strengths and weaknesses associated with the matrix organizational structure:

\section{STRATEGIC STRENGTHS}

- Permits more attention to each dimension of strategic priority.

- Creates checks and balances among competing viewpoints.

- Facilitates simultaneous pursuit of different types of strategic initiative.

a Promotes making trade-off decisions on the basis of "what's best for the organization as a whole."

- Encourages cooperation, consensus building, conflict resolution, and coordination of related activities.

$\square$ Arrows indicate reporting channels.

\section{STRATEGIC WEAKNESSES}

प Very complex to manage.

- Hard to maintain "balance" between the two lines of authority.

- So much shared authority can result in a transactions logjam and disproportionate amounts of time being spent on communications.

- It is hard to move quickly and decisively without getting clearance from many other people.

- Promotes an organizational bureaucracy and hamstrings creative entrepreneurship

2.12 POLITICAL/ ADMINISTRATIVE PERSPECTIVE ON STRUCTURE
The structure of government directly addresses the issue of authority and responsibility for performing public functions. The formal structure of government as it relates to service delivery of any type must be viewed in the context of established parameters of public policymaking. When the structure of government changes the parameters of the policymaking process alters. The conditions, influence, and impact of service delivery and distribution are altered. The needs and demands that citizens place on government certainly has the potential to influence funding priorities or for 
that matter what jurisdiction may provide a certain commodity. The way in which those demands are articulated or processed is conditioned by the structure of government. Some structures may facilitate the translation of those demands into increased expenditures; others may inhibit the translation of those demands. For example, federal systems or structures tend to retard the translation of demands into public policy. The federal system is replete with checks and balances that slow hasty actions of government.

Yet another example of the importance of structure on service delivery refers to the geographic aspect of providing public services in general and transit services in particular. Some services such as transit have clearly defined areas of benefit; rail and bus lines extend only so far. Individuals who live outside the service area or do not have the price of the fare simply do without. Under such a decentralized system/structure, any individual who is dissatisfied with the decision of the majority population to provide or not provide the transit service may pursue one of two options. One, they may seek to change the decision of the majority or, two they move to an area where the decision of the governing jurisdiction is consistent with their preferences.

Assuming citizens have equal political influence to sway decision makers and equal ability to move freely to a more accommodating jurisdiction reflects a relatively efficient, quasi-market mechanism for allocating transit service. In theory, such a decentralized structure for financing and delivering transit service would promote efficiency in individual preferences in a nondiscriminatory manner.

There are two problems with this theory: first, political power is not evenly distributed among the various segments of the community (e.g., business, environmental, ethnic, and or socioeconomic). One group's political support for more, less, or different transit service may or may not influence the decision-maker; and second, the opportunity to move freely between local jurisdictions is not equal. The presumed option to vote with your feet is not a very realistic option for some, indeed many, when you consider the finite resources, limited knowledge, and conflicting interests and priorities citizens-consumers must contend when making such a decision.

Some structures of government are like well oiled machines; they translate public inputs (demands/needs) into public policy relatively fast and effortlessly. We tend to say that such structures are more responsive than others. Additionally, some forms of government may be more responsive to different kinds of demands, demands by different segments of the community (i.e., business interests, unions, and or the elderly). If one form (structure) 
of government consistently favors one group over another, a structural bias is manifest toward a particular group. Bias can be demonstrated by comparing different structures in basically similar situations.

Responsiveness is only one dimension of service delivery/performance; efficiency, effectiveness, and equity are others. Efficiency is a measure of the relationship between the resources used/expended and outputs produced. One structure is said to be more efficient than another if it produces more "bang for the buck". Effectiveness is a measure of the extent to which an entity accomplishes it goals, weather reducing crime or increasing rider-ship. In brief, one structure is more effective than another if it is more successful in solving problems with which it has been charged to remedy. Once again, a comparative analysis is an effective measure performance.

Equity is a complex but nonetheless important civic value that should also be considered in relation to other policy goals in a democratic society. More than twenty years ago Rich (1982) suggested that the questions of equity focus on the following:

What is to be equalized? Are they related to activities, outputs or outcomes?

What is the basis for equalization? Is it need?

What is the appropriate unit?

$\square$ What is the appropriate level of equalization (whether minimum standards or uniformity)?

Policy analysts, in the past, have described and explained service disparities by searching out the influence of government structure on delivery and distribution. The importance of structure is manifest in that some consumers are made better or worse off. Structure establishes the formal institutions of policy making as well as the scale and size of the service jurisdiction. Structure has significant implications on planning, financing, production, and delivery. Size and scale of service area jurisdiction do influence demand, capacity, and accessibility. These factors help to shape the quantity and quality of services made available to citizens. Structure can either mute or exacerbate conflict. Structure is an intangible governing partner that impacts bureaucracies and organizational arrangements and exert influence on policy and service delivery. Structure affects the process of decision making within bureaucracies or service arrangements. In short structure matters. 
Responsiveness, efficiency, effectiveness, and equity are often in conflict with one another but not always. The realities of politics compel policymakers and public administrators to identify and develop a tolerable balance of these policy goals. A balance that is acceptable among the general public, professional constituencies, and the clientele they serve. No single structure is likely to facilitate all equally well.

The consequence will be performance gaps. These gaps occur when there is a difference between what the constituencies/clienteles expect and what the entity produces. Studies that analyze service distribution and delivery may find performance measurement a useful indicator of goal achievement.

2.13 IDENTIFICATION OF TRANSIT TYPES WITH ORGANIZATIONAL STRUCTURES
State of Florida. Among the largest transit agencies (one hundred or more peak vehicles) within the State of Florida two organizational structures are prevalent, namely, the functional organizational structure and the decentralized business units structure. Jacksonville Transportation Authority (JTA), Hillsborough Area Regional Transit (HART), Central Florida Regional Transportation Authority (LYNX), and the Tri-County Commuter Rail Authority (TRI RAIL) are operated as independent transit authorities, also known as special authorities, a term we will use in our discussion or reference to independent transit authorities. Whereas, MiamiDade Transit Agency (MDTA), Broward County Mass Transit Division (BCT), and Palm Beach County Transportation Agency (PALM TRAN) are operated as divisions or departments of the local government. With the smaller transit agencies the dominant organizational structure is decentralized business units structure as they function as divisions or units of the local jurisdiction.

National Perspective. At the national level, of the top thirty-five largest transit agencies (based on 1999 data from APTA: Number of peak vehicles) there were twelve operated as divisions/departments of government, and twenty-three operated as independent authorities. This means that the dominant organizational strategy among the thirty-five public transit agencies was the functional organizational structure. Twenty-three agencies subscribed to the functional organizational structure, while the remaining twelve agencies subscribed to the decentralized business unit structure. The largest five public transit agencies, namely, The Metropolitan Transportation Authority of New York, Los Angeles County Metropolitan Transportation Authority, Regional Transportation Authority of Chicago, Southeastern Pennsylvania Transportation Authority, and New 
Jersey Transit Corporation (these agencies operated in excess of 1,000 peak vehicles) all adopted the functional organizational structure.

2.14 TYPES OF TRANSIT ORGANIZATIONAL STRUCTURES
Formally, and traditionally, public sector structures are viewed from a macro level and are generally discussed in the context of operational management, control and ownership. To fully understand these characteristics of structure it is sometimes best to examine structures according to types of structures. We have identified and discussed the different types of general structures; the following discussion provides focused attention on public transit systems. Using a modified version of Perry's (1984) typology of public transit systems, we will investigate the relationship between structure and performance.

Perry suggests five different structures namely (1) General Government/ Public Management (GGPM); (2) Special Authority/Public Management (SAPM); (3) General Government/Contract Government (GGCM); (4) Special Authority/contract management (SACM); (5) private ownership/ private management. This study will adopt and focus on the first four.

For purposes of illustration, Table 1 shows the structural categorization of Florida public transit agencies. Except for SACM (that is, special authorities with a contract management structure) the table underscores the fact that Florida is quite typical of the rest of the country in terms of public transit structures. (See Table 2 which is a sample listing of public transit agencies nationwide. For a much more comprehensive view, see Appendix 1.) 


\section{Table 1: Florida Transit Agency Organizational Structures}

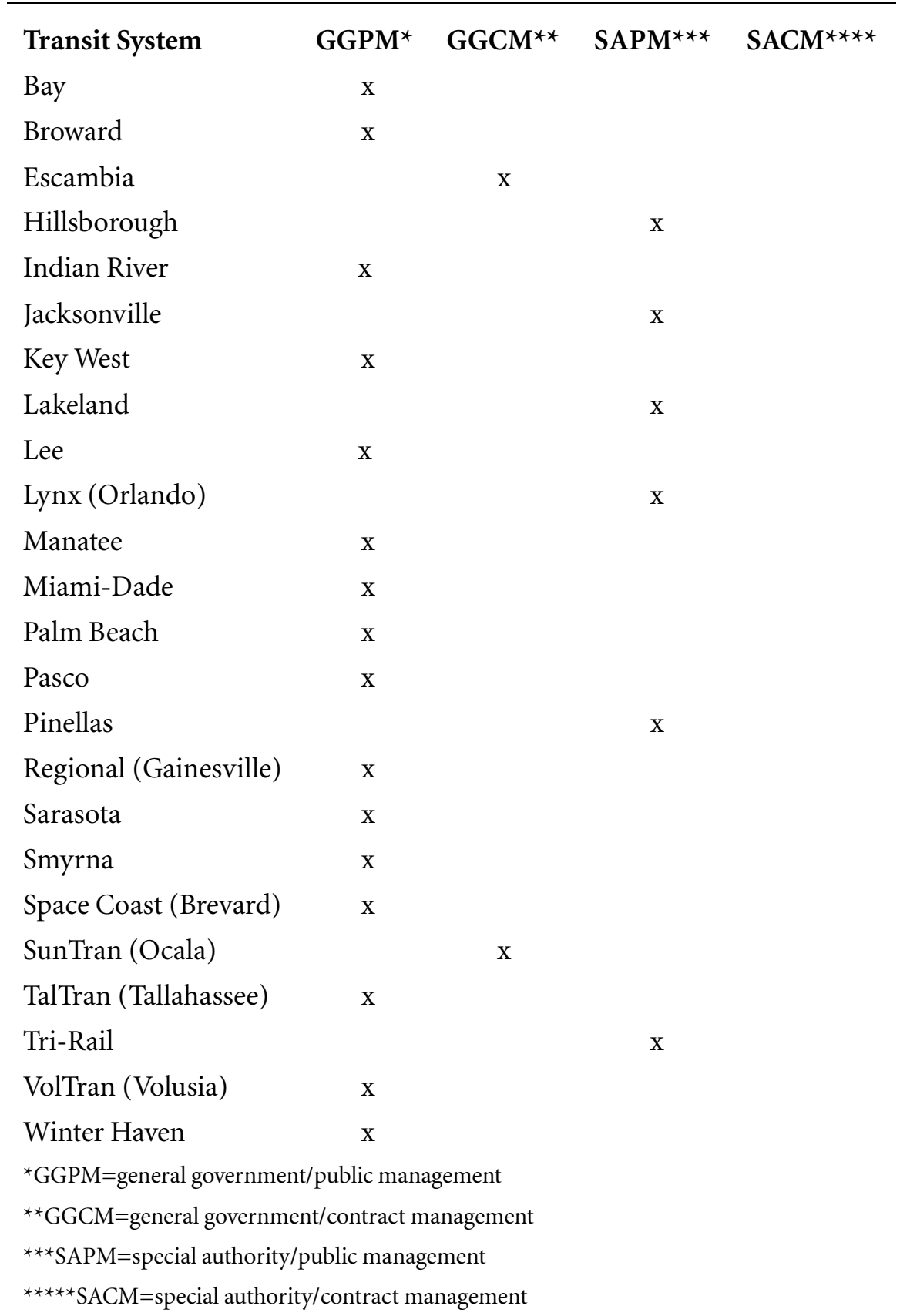


TABLE 2. Sample List of National Transit Agencies According to Organizational Structure

\begin{tabular}{llll}
\hline AK & Municipality of Anchorage & $\begin{array}{l}\text { Municipality of Anchorage - Public Transportation } \\
\text { Department }\end{array}$ & GGPM \\
AR & University of Arkansas & University of Arkansas, Fayetteville/Razorback Transit & SAPM \\
CA & Golden Empire Transit Dst & Golden Empire Transit District & SAPM \\
CA & Long Beach Publ Transp & Long Beach Public Transportation Company & SAPM \\
CA & SunLine Transit Agency & SunLine Transit Agency & GGCM \\
CT & New Haven-CT Transit & Connecticut Transit-New Haven Division & SACM \\
PA & SEPTA & Southeastern Pennsylvania Transportation Authority & GGCM \\
SC & Greenville Transit Auth & Greenville Transit Authority & GGCM \\
TX & MetroTransAuth HarrisCnty & Metropolitan Transit Authority of Harris County, Texas & SAPM \\
TX & City Transit Mgmt Comp & City Transit Management Company,Inc & SACM \\
TX & Waco Transit System & Waco Transit System, Inc. & SACM \\
TX & Beaumont Transit System & Beaumont Transit System & SACM \\
PA & Cambria County TA & Cambria County Transit Authority & GGPM \\
WI & Oshkosh Transit System & Oshkosh Transit System & GGPM \\
WI & Sheboygan Transit System & Sheboygan Transit System & GGPM \\
WY & City of Cheyenne Transit & The City of Cheyenne Transit Program & GGPM \\
GGPM=general government/public management & \\
GGCM=general government/contract management & \\
SAPM=special authority/public management &
\end{tabular}

PUBLIC OWNERSHIP
General Government transit agencies are transportation departments or divisions of local (city/county) governments. These, like other general government or general purpose entities are directly accountable to a city or county council or commission and receive funding from the local government of which they are apart. These are referred to in this study as general government public management (GGPM). This means that they are publicly owned and publicly managed. Their jurisdictional authority is determined, for the most part, by the local council or commission. Most transportation departments in the United States are or this type. Perry's classification of general purpose government or (general government transit systems) is further subdivided into two. These are, according to him, general government / public management, and general government/ contract management. The common element between all forms is ownership. 


\section{STRENGTHS}

With public ownership, a municipality retains substantial control over transit provision. This allows government to address the "public service" aspect of public transportation and use general revenue to subsidize money-losing services. Government agencies have taxing authority that is obviously not available to private agencies, and they often have access to low-cost federal and state funds not available to the private sector. Government control also makes service provision responsive to the political process. This is likely to be viewed as strength by politicians and bureaucrats, though it is likely to be a liability financially, as voters generally will make voting decisions based on something other than strictly financial issues.

\section{WEAKNESSES}

Inefficiency is the most important weakness of public ownership. Because they have access to other funds to use to subsidize service, many public transit agencies operate unprofitable routes. Lack of competitive pressure also tends to stifle innovation and the adoption of new technology.

General purpose units, on the other hand, are in competitive political environments and transportation, not being a politically popular service delivery area, can and many times do, lose out in funding priority to more politically appealing service delivery areas, such as, public safety, or education.

- It is questionable whether GGPMs have the necessary room for innovation, creativity and change that other transportation structures might enjoy.

GGPMs are much more subject to political winds of change than say special authorities from the stand point of change in elected personnel which can result in change in administrative heads or directorships; consequent change in policy and program directions, also change in budgetary priorities and levels of funding.

SPECIAL AUTHORITIES (OR INDEPENDENT AUTHORITIES)
These Special Authorities are special purpose governments created by local or state government to provide public transit as a service function. These are referred to in our study as special authorities/public management (SAPM). Typically, the scope of authority of special authorities is determined by the creating government(s) but they are generally given taxing, personnel and policy making powers that enable them to function as a government within their own right but within the confines of executing an 
authorized single purpose of service delivery, in this case, in the area of public transit. Growing out of this advantage are what others have described as innovation and flexibility that can lead to greater efficiencies in the provision of transit service. Perry's formulation identifies a subset of special authorities referred to as special authority/contract management (SACM). Again, what links special authorities, irrespective of type, is that they are all publicly owned. Public ownership is the common element among all types of transit structures. Both types of publicly owned transit agencies--general government and special authority--share a management style called contract management. In sum, there are two broad forms of functional transit organizations: General Government (GG) and Special Authority (SA); Related to these are two management approaches: Public Management (PM) and Contract Management (CM). A combination of these separate but related organizational and management forms, for the purpose of analysis, enables this study to identify four forms of public transit systems, which are general government / public management (GGPM), general government/contract management (GGCM), special authorities/public management (SAPM), special authority/contract management (SACM).

\section{ADVANTAGE}

Special authorities are generally viewed as non-politically free-standing entities in the sense that they are not usually targets of continuous, intense political controversy. They at least have the potential of greater administrative flexibility in hiring, firing and taxing. They are perceived to be one step closer to market-like entities, a perception which may not always be substantiated by reality.

\section{DISADVANTAGE}

Many or most special authorities are required to find their own funding sources and this could mean that these are special authorities that may have to compete with general purpose governments for the same tax sources, for instance, the property tax. Depending on the local government ordinance, financing authority or state authorization tax revenues can prove difficult to obtain and this, ironically, can cause a special authority to be more dependent on their creating government(s) when quite the reverse was originally intended. 
2.15 CONTRACT MANAGEMENT
As it has been indicated above, the new paradigm in public transit includes greater emphasis on different approaches to management rather than the traditional emphasis on formal structures and the attempt to measure performance of these formal structures in the context of efficiency.

Approaches to public management as a new emphasis on structural studies designed to better understand the relationship between structure and performance are quite consistent with the new paradigm in public transit.

An important form of management structure relevant for this project's focus is contract management. A discussion on this management form follows.

Public Ownership/Contract Management. The use of contract management for transit is one way to introduce private-sector management organization intro public transit agencies. This is an important dimension of transit management that merits attention in our study. The United States initially experienced a shift from privately run and privately financed transit systems to publicly run and publicly financed systems. At the start of the twenty first century there are simply very few privately owned municipal transit systems in existence in the United States. In spite of this, there is still a substantial private sector presence in transit provision. This private sector involvement results from an additional transformation of municipal transit in America: that is, while transit systems remain extensively financed by governments at all levels, the management of many systems is returning to private companies. (This is not to be confused with replacement of ownership; transit systems remain public in ownership. Private sector involvement is simply an incorporation of private sector management techniques or emphases in the administration of public transit systems.) It is this change that creates a unique opportunity to examine the different management regimes of transit agencies throughout Florida and the rest of the nation and examine how those organizational forms affect the provision of transit services.

The lure of efficient provision of public services is powerful for local governments, but outright privatization of transportation services is often not a viable alternative. Cities may be reluctant to give up the level of control that exists when goods are produced in the public sector. Furthermore, privatization may also interfere with the "public service" aspect of transit provision. Consequently, outright privatization of transportation agencies is uncommon, and municipalities are much more likely to rely on the formation of public/private partnerships. Often times this partnership takes the form of a public transit agency where the managerial functions have been contracted out to a private transit management company. Cities may 
rely on this arrangement to provide the discipline of market forces while still ensuring control by local governments.

This type of compromise is even found in the overall structure of municipal government. Some municipalities rely on the "public" management of elected politicians, while others prefer to "contract out" management to a professional city or county manager. Deno and Mehay (1987), DuffyDeno, Dalenberg (1990), as well as others, have done interesting studies to determine whether these different management structures have consequences for municipal fiscal performance. Conclusive results have not yet been reached in these broad studies on the effects of differences in management structure. The study by Deno and Mehay (1987) examined the relationship between municipal expenditures and the form of city government. They concluded that although there was a small positive relationship between the presence of a city manager and reduced spending, the relationship was not statistically significant. Downing and Bierhanzl (1998) in their recent study reached a similar conclusion. Duffy-Deno and Dalenberg (1990) were able to identify differences in "elected mayor/council" cities and "city manager" cities with respect to capital stock and capitallabor ratios, but they were unable to come to definite conclusions with respect to "efficiency". This largely reflects a problem similar to one that exists in public transit literature - what does it mean to speak of an "efficient" public sector entity? Hayes and Chang (1990) similarly find no measurable difference in the efficiency of different types of city management.

A narrower test of the effects of different management structures is appropriate for our analysis of public transit service. Fortunately, there has been more work that specifically addresses transit service provision than there is for municipal management in general. It is this type of analysis that relies on the distinction between transit agencies where the management is contracted out to private company and transit agencies that are managed by the municipality that operates them. It is also useful to include in this comparison a third category: public authority transit agencies. These public authorities can be managed either by government employees or privatesector employees. However, there is sufficient difference in the organizational structure of public authorities and municipal governments that they can be treated as separate types. Most importantly, special authorities focus on one particular service, while municipal governments are responsible for a wide range of dissimilar services and other governmental responsibilities. 


\section{STRENGTHS}

Efficient service provision is the primary strength of private management and the main reason behind the adoption of the contract management arrangement. Transit management companies have substantial expertise in the industry - expertise that is likely to be missing in a municipal government, especially in smaller cities and counties. Also, private management has a strong incentive to provide a given level of service at the lowest possible cost. Since there are several management companies that could potentially contract with a municipality, there is competitive pressure on private managers to provide a high level of service at a low cost. This incentive is largely absent in the public sector management. With bureaucratic management, where there is no possibility of alternative providers to act competitively, high costs and inefficient provision can be sustained indefinitely. These same competitive pressures create an incentive for innovation in the private sector that is largely absent in the public sector.

\section{WEAKNESSES}

Since local governments still retain substantial oversight of transit operations, the combination of public ownership with private management may not be able to realize all the possible benefits described above. Management often faces significant constraints with respect to extent and level of service provision. These constraints are essentially what prevent agencies from operating "like a business."

2.16 DISTINCTION BETWEEN SERVICE CONTRACTING AND MANAGEMENT CONTRACTING
Since the current study is focused on the organizational and management structure of transit systems, a comparison of publicly and privately managed transit systems must be sure to distinguish between agencies where the management is contracted out and agencies where individual services are contracted out. This will often be a difficult distinction to make. Many agencies that rely on contracting are involved in contracting a mix of services. It may be even more common for an agency to contract with a private firm to operate specific routes than it is to contract for private management with services being provided by government employees.

This is one area that highlights the importance of the current research. Since contracting out for services is a more common practice it has received more attention in the literature. Often, the term "contracting" is used to refer exclusively to contracts related to service provision; management services are not even considered. An excellent example can be found in Teal (1988) "Public Transit Service Contracting: A Status Report". This 
article reports the results of a survey of almost all transit agencies in the U.S. and (as the title implies) details the extent of service contracting. The author finds that service contracting is uncommon, accounting for less than ten percent of service miles. Even that limited use is concentrated in smaller transit agencies, or for smaller services within a larger agency. Anthony Simpson (1985) also specifically examines service contracting. While the paper recognizes the efficiency gains from private contracting mentioned above and provides several guidelines for structuring service contracts, the research does not address the area of management contracting.

The effects of contract management have received less scrutiny and therefore require closer examination. Furthermore, changes to transit system management structure often involve combinations of contracting and public provision. To illustrate the difficulty involved, research by Karlaftis and McCarthy (1999) was directed at the effect of "privatization" on transit costs. While their work is able to gain detail by focusing narrowly on one U.S. city, Indianapolis, they are forced to analyze a situation where there are several dimensions to the notion of "privatization." Rather than a shift from a publicly owned and operated to a privately owned and operated service, the city of Indianapolis made a complicated transition over the course of several years.

Mixed-Systems. The Indianapolis Public Transportation Corporation (known as METRO) was a publicly owned and operated municipal transit system. Over the course of several years in the mid 1990s the METRO system went from an essentially public transit system to a mixed system consisting of: a streamlined version of METRO operating the majority of the old bus routes under contract from the city, 15 routes operated by a private company (ATE Management \& Services), ADA services provided by a different private contractor (Transportation Management Services, Inc.), and a new Office of Mobility Management, run by a third private company, to provide customer service and quality control. The results of the research are consistent with other work that has found cost savings in privatization; in this case a $2.5 \%$ reduction annually in operating costs. The details of the study do illustrate the difficulty in identifying or defining a "privately managed" agency.

To avoid problems associated with this type of mixed regime, researchers can attempt to compare transit systems that are wholly public with ones that are wholly private. As indicated before, however, the relative scarcity of private sector municipal transit providers makes this difficult. A paper by Morlok and Viton (1985) was able to demonstrate substantially lower 
service costs for private transit service providers when compared with public providers. To get a large enough sample of comparable systems, the authors had to not only include several agencies outside the United States but also had to look at several U.S. agencies over time to capture the transition from private to public. When comparing entire systems in this manner the authors were able to document private systems costs that were approximately fifty to sixty percent of public sector costs. They find similar results in instances of private firms taking over provision of publicly operated systems. While their research is broad, it did not specifically address the issue of systems that are publicly owned, but privately managed.

Research by Anderson (1983) attempts to sort out the effects of different management structures as well as changing levels of transit subsidy during the years 1960 - 1975, a period of substantial transition in the transit industry. She includes six types of management structure in her analysis by dividing transit agencies into groups depending on whether they are operated by: private firms, public utilities, contract management, municipalities, transit authorities without taxing authority, or transit authorities with taxing authority. The data covers a period when there was substantial transition from private transit operation to other forms, so the results of the research are presented as a comparison between private operation and the other forms. The results are mixed, but the author does highlight the following findings: "Over the period 1960 - 1975 transit riders have lost service and efficiency but gained lower fares when privately owned or contract-managed transit converted to utility ownership. In contrast, conversion of private to public ownership with contract management has offered less service and efficiency than municipal management and slightly higher fares."

More recent work has focused specifically on these "mixed systems": public agencies with private contract management. David Good (1992) specifically examines the behavior of managers in publicly owned transit systems where top-level management is contracted out. This study describes the well-known causes of public sector managerial inefficiency due to two factors: a general principal-agent problem (found in both the private and public sectors) and the theory of bureaucratic behavior (specific to the public sector). While the author expects to find differences between privately managed and publicly managed agencies, he notes that managerial discretion is usually restricted in these types of contractual arrangements. Transit employees are public employees in either case, and management contracts generally specify which routes are to be operated. Private managers, therefore, have substantially less discretion to make labor force changes (on the input side) or service changes (on the output side). Never- 
theless, private managers should have incentives for efficiency because the contracting of management services tends to be competitive. Any gains that are realized through successful management can be helpful in securing future contracts.

The result of Good's research shows that privately contracted management is more technically efficient than public management. This result means that private managers are able to get more output from a given set of resources. The magnitude of the difference is small, however. The data indicate that private management is only about $2.6 \%$ less costly than public management. Interestingly, the research also shows that private management still demonstrates measurable inefficiencies (in some cases as large as those of public managers). Additional research is necessary to explain the possible sources of these inefficiencies. Also, further research is needed to determine whether other aspects of transit agency organization (e.g. the presence of city managers, or separate transit authorities) can contribute to different managerial outcomes.

One great difficulty that runs throughout these studies of transit management is the issue of measuring outcomes. Every assessment of the effects of different management forms must specify a way to evaluate the performance of transit agencies under different structures. Whether these measurements purport to measure "outcomes", "performance", "efficiency", "productivity", "service", or some other variable, the result of transit operations must be quantified. This is a substantial problem when trying to compare different studies. The simple fact is that there is no one correct way to measure the output of a transit agency. The next section of the literature review highlights the developments of transit performance measures in the economics literature.

2.17 MACRO VS. MICRO LEVEL STRUCTURE
It is appropriate to pause at this point after reviewing the wide variety of organizational structures that we have subsumed into four broad categories, as they relate to the study of public transit systems. The other aspect of this study, performance, deserves some reference here, since the study recognizes that structure as discussed so far, speaks to the macro level aspects of structures. There is a micro level component of these structures that very likely will require our attention as we seek to investigate the relationship between structure and performance.

To begin with, the literature recognizes that the micro-level of organizational structure is a significant starting point in understanding the relationship between structure and performance. What is it, for instance, 


\section{Section 2. Literature Review}

about two organizations of the same structure purported to be appropriate for both public transit systems, and notwithstanding, one transit unit has high performance results while the other experiences poor performance? This is not an easy question to answer, but when the researcher probes the macro-level characteristics of the transit structures, he or she is likely to be moving in the right direction for reliable answers.

Yelsey (1984) satellite model (Fig.1) helps as a starting point in identifying several aspects of the micro-level of organizational structure. The various elements of his model (along with others not mentioned in his model) are likely predictors for explaining the "influences" on performance in organizations. Notably, these elements can be viewed as internal and external to the organization. Internally, for instance, the nonhuman resources imply quality and quantity of capital assets that are utilized within the organization; likewise, human resources element of the model refers for instance to the quantity and quality of personnel at line, managerial, or policy making levels. Knowledge and training levels of personnel (in strategic and nonstrategic capacities), specific to the functional tasks, can and do impact performance.

\section{FIGURE 1: Satellite Model of Organization Performance}

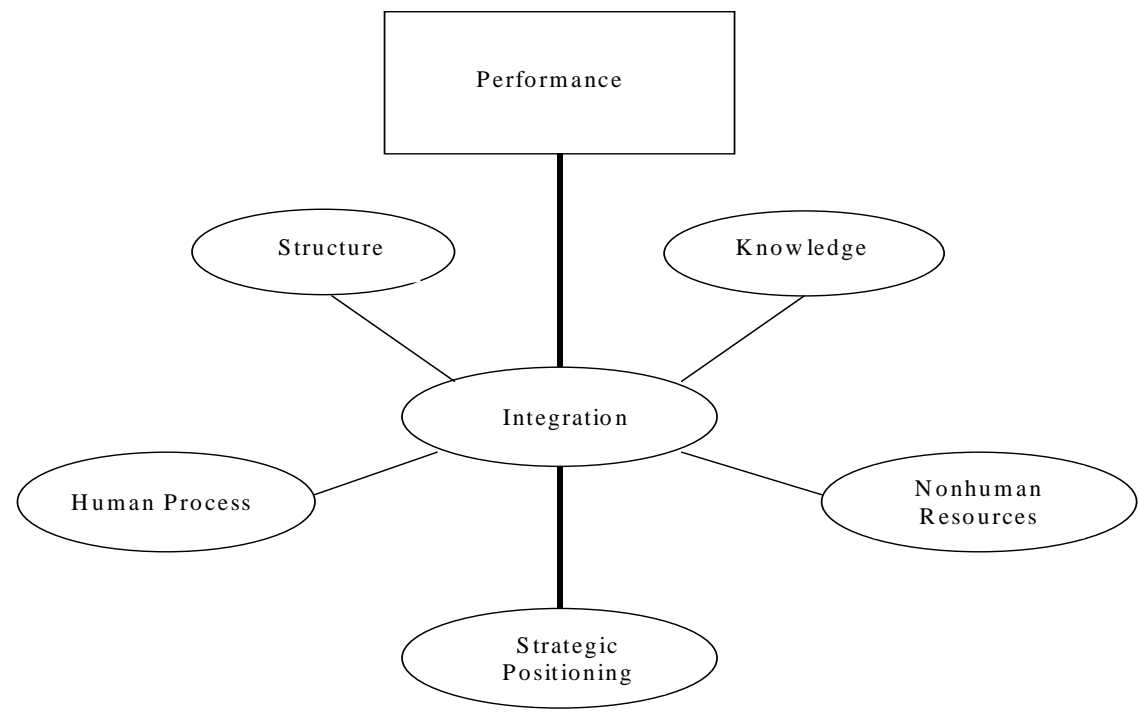

Source: Alan A. Yelsey, "Strategies and Actions for Improving Organizational Performance," Academy of Management Review, June 1984, p. 25.

As they vary from one organization to another so will performance even though both organizations are of the same structural type. Executive Orders, statutes, ordinances, and political climate, as external influences 
can also determine the degree of integration as manifested daily through coordination, control, and implementation of transit policies.

Another significant influence on performance at the micro-level of organizational structures is incentive systems. Johathan Karpoff (2001) points this out in that study also reminds us of the importance of looking at the micro-level for possible answers to questions raised about comparative performance between or among organization structures at the micro-level. Galunic and Eisenhardt (1994) in a review of empirical studies on the relationship between structure and performance identified studies that similarly recognized the value of studying the organization structure at the "intra-corporate" or micro-level. Further, the study by Chow, Henriksson and Heaver (1995), examines the hypothesis that the best fit between strategy and structure leads to improved performance; here again, these scholars sought to better understand the relationship between structure and performance at the micro-level. A search for understanding of such a relationship at the micro-level, it must be pointed out, cannot rely exclusively on quantitative analysis; qualitative analysis is critical to achieving insights on the relationship between structure and performance.

2.18 MEASURING PERFORMANCE
Of course, the idea that different management structures can lead to different outcomes for transit agencies requires a specific method for evaluating outcomes. Typically, researchers are interested in transit performance. Before any study is developed, however, there must be a very clear statement of what the concept of performance means to a transit agency.

The problem of measuring performance is well recognized in the business management literature. Tracking strategy, or evaluating progress toward established objectives, is an important task in strategy implementation as it relates to an organization's structure and culture. There are basic considerations that must be considered in putting together a performance measurement system. A few of these considerations are selecting adequate and measurable performance measures, setting performance standards, and designing appropriate reports. A strategic performance measurement system requires reporting not by profit center or cost center but by strategic business unit [SBU] (Strickland, 1987; Sridharan and St. John, 1998). Most management reporting is geared to focus on the bottom line. For many business units, however, profit is not the pertinent measure of a unit's strategic performance. In selecting performance measures, only those measures that are relevant to the strategies adopted by each SBU should be chosen. It is important to ensure, when setting performance standards, that targets or expected values are established so that they are consistent 
with both the organization's strategic position of its business units and the strategies selected. Finally, reports should focus management attention on key performance measures.

Ordinarily for a business, "performance" can be measured simply by profit and loss analysis, which tells us about the efficiency of resource use. An important question for transit is how to measure performance in a business that is not concerned with profit in the traditional sense. Fortunately, economists have done extensive work in the area of public transit system performance and this literature review will draw heavily from those sources. Given the nature of this research, it will be necessary to carefully select well established transit performance measures that are appropriate, since this study does not address issues of profitability or the bottom line, at least not in the manner that typical business enterprises do.

In the public finance literature, discussions of efficiency usually focus on cost measures. A service is said to be produced more "efficiently" if it involves the production of the same level of output at a lower cost. This definition of efficiency is consistent with the term's general use in business and economics. The Downing and Bierhanzl (1998) and Hayes and Chang (1990) articles cited above use precisely this definition when measuring the efficiency of local government services. This efficiency definition is also used in the transit literature.

More often, however, researchers are interested in documenting "performance". This is a more difficult term to define precisely. Efficiency has but a single fundamental unit of measurement: dollars. That is, a producer who is able to provide a given level and quality of service at the lowest cost is said to be the most efficient. This is true even when the measure of "efficiency" is not specifically stated in dollar terms. For example, several transit performance studies have used vehicle miles per employee as a measure of efficiency. Although the measure is not expressed in dollar terms, it is clear that a transit agency with a higher ratio of vehicle miles to employees will necessarily be producing those miles at a lower cost, assuming all else is the same. Performance, however, is a term that incorporates many possible dimensions, since there are many possible performance goals that can be pursued. This is an issue that researchers have had to grapple with throughout the transit literature.

A detailed exposition of the issue is provided in Productivity, Efficiency, and Quality in Urban Transportation Systems by Tomazinis (1975). The author argues that efficiency can be viewed from four perspectives: the operator-supplier, the user-consumer, the government, and society at 
large. To simplify analysis, the first two groups are treated as one and the last two groups are treated as one. This simplification is justified by arguing that transit had become an increasingly publicly provided good (or at least publicly regulated), and that as a consequence transit had increasingly taken on the character of a public service.

Even with this simplification, Tomazinis produces an extensive collection of measurements to document performance. From the operator's point of view there are five important areas where efficiency objectives can be realized:

1. Unit costs

2. Input of resources

3. Relative distribution of costs

4. Provision of service

5. Collection of revenue

Each of these areas can be measured in a number of ways. For example, six different ratios are suggested for use as unit cost measurements of efficiency. They are:

Operating expenditure per vehicle-mile

$\square$ Operating expenditure per passenger-mile

$\square$ Operating expenditure per passenger

- Direct cost of conducting transportation per vehicle-mile operated

D Direct cost of conducting transportation per passenger-mile

$\square$ Direct cost of conducting transportation per passenger

Similarly, ratios can be calculated for each of the other efficiency objectives listed above. Altogether, Tomazinis provides no fewer then twenty-seven different "analytically significant" measures to evaluate the efficiency of transit provision. And this is only from the providers' point of view. Transit users also have areas of concern for the efficiency of transit provision. The four areas of importance to users, according to Tomazinis are:

1. Cost of travel

2. Quality of travel

3. Reliability of service

4. Safety and security

As with the transit providers' efficiency considerations, each of these areas of concern can be measured by a variety of ratios. There are a total of four- 
teen "significant efficiency indicators" for transit users. While the author's measurements are generally termed "efficiency" measures, they capture a wide variety of factors. As the book's title suggests they are an attempt to measure productivity and quality as well as efficiency.

The very large number of measurements presented is evidence of the large number of variables that are of interest to transit providers and users. While much detail can be captured in these measures, the large number of them presents a substantial weakness. Such a variety of measurements make it nearly impossible to compare one agency to another, or even to evaluate the same agency across time. There is no weighting scheme to determine which measure is more important. For this reason much of the literature in the intervening years has struggled to pare down the number of transit performance measures to a more manageable set.

Talley and Becker (1982) several years after the Tomazinis' book, attempted to unify the ideas of both efficiency and performance. Their work pushed toward the other extreme, attempting to distill transit performance into a single measure. Like virtually all other researchers in this area, Talley and Becker explicitly recognize the inherent difficulty in identifying a single measure of performance for transit agencies. Their solution was to draw a parallel between the behavior of profit maximizing private firms and public transit agencies. While private firms must pursue a costminimization strategy to insure maximum profit, the authors suggested that public transit agencies must also follow this strategy.

They recognize the general argument that transit should be concerned with both efficiency and effectiveness. This encompasses the generally accepted definition of efficiency as cost-minimization and effectiveness as a measure of the extent to which a system achieves its objectives, such as maximum ridership, accessibility, or coverage. Maximum effectiveness is achieved when the agency minimizes cost for a given level of ridership (this is "actual deficit minimization" in the authors' terms) thereby allowing the agency to expand ridership until it reaches a pre-specified deficit constraint. The authors further argue that the transit route should be used for the unit of analysis, and that the "transit deficit per passenger" is the one appropriate measure of the success of a route. Routes can then be ranked according to per-passenger deficit and the results compared. This approach is consistent with the objective of maximizing ridership subject to a maximum allowable deficit. The authors assert that this is a superior measure of transit success because it includes both cost ratios (which captures "efficiency") and numbers of passengers (which captures "effectiveness"). 
While there is a certain logic to this argument, it is likely that the multifaceted nature of transit service provision simply cannot be captured in one single measure, but must be evaluated systematically with a set of carefully designed measures. Benjamin and Obeng (1990) state the problem quite succinctly in the very first sentence of their Transportation Research paper. "The need for performance measures has led to the development of a large number of ad hoc measures of productivity, efficiency, and effectiveness." Their approach to the ad hoc nature of the process is to focus on "total factor productivity" as a measure of performance. The authors' definition of total factor productivity is consistent with the generally accepted understanding of the term productivity: "total output per unit of total resources expended". For purposes of the study output was measured in terms of passenger miles and vehicle miles, and inputs were measured in terms of labor operating cost, fuel price, and number of vehicles. While this method does give the authors a limited number of variables to measure productivity, their analysis demonstrates that there is not necessarily a relationship between these productivity measures and measures of efficiency. Their efficiency measures consist of maintenance hours per vehicle, number of employees per peak vehicle-mile, average miles per hour, and proportion of time a vehicle is operating when it is en route.

2.19 CONSENSUS ON MEASURING TRANSIT PERFORMANCE
The work of Benjamin and Obeng succeeded in maintaining a small number of measurements, but at the cost of eliminating important information about effectiveness. A fruitful approach to addressing this issue can be seen in a 1985 work by Fielding, Babitsky, and Brenner (and also in earlier works by these and other authors). Their important contribution to solving this problem lay in a systematic attempt to define the nature of transit performance. In the authors' conceptual model, cost efficiency, service effectiveness, and cost effectiveness are the three important components or dimensions of performance.

Starting with nearly fifty different performance indicators, the authors used extensive analysis to determine which measures were "key" indicators of performance. Using Section 15 transit data, they identified seven indicators that represented what they called "the key underlying dimensions of performance." The most informative "global measures" that they found were revenue vehicle hours per operating expense, unlinked passenger trips per revenue vehicle hour, and operating revenue per operating expense. These measures are important because of their link with the three performance components mentioned above. 
Specific areas of performance (that are key components of overall performance) are addressed by the remaining four measures. Vehicle hours per employee is used as a measure of labor efficiency, vehicle miles per peak vehicle required is used as a measure of vehicle efficiency, vehicle miles per maintenance employee is used as a measure of maintenance efficiency, and millions of vehicle miles per accident is used as a measure of safety. The authors place a great deal of confidence in these measures to allow transit managers and government officials to make informed decisions about transit systems.

Cervero (1984) uses an earlier version of these same ideas (from a 1978 paper by Fielding, Glauthier, and Lave) to measure performance impacts of transit subsidy programs. He picks up on the theme of three categories of transit performance indicators, dividing the measures into efficiency indicators, effectiveness indicators, and overall indicators. All of these indicators are measured using ratios similar to the ones used by Fielding, Babitsky, and Brenner. This work shows that even as of the mid 1980s there was a consensus developing that the important dimensions of transit performance should be measured by a relatively small set of ratios.

More recently, Karlaftis and McCarthy (1997) use the more rigorous technique of factor analysis to define this small set of performance measures. Using terminology similar to Cervero they define three "factors" or dimensions of performance: overall performance (which captures revenues and costs), efficiency (which captures cost efficiency as well as labor and vehicle utilization), and effectiveness (which captures service and accessibility). Each of these performance dimensions is correlated with the others, but each provides a distinct contribution to the evaluation of system performance. The authors use factor analysis to identify indicators (measurable variables) that can best explain or account for each of the factors. The result is a model in which the following indicators are used to quantify each factor (factors are in bold with the indicators listed under each one):

\section{OVERALL PERFORMANCE}

$\square$ Ratio of operating revenue to operating cost

$\checkmark$ Passengers per operating expenses 


\section{EFFECTIVENESS}

$\square$ Passengers per capita

$\square$ Passengers per vehicle

$\square$ Passengers per revenue vehicle mile

\section{EFFICIENCY}

$\square$ Revenue vehicle miles per employee

$\square$ Revenue vehicle miles per vehicle

$\square$ Revenue vehicle miles per operating expense

Interestingly, these indicators are very similar to those identified more than a decade earlier by Fielding, Babitsky, and Brenner. Karlaftis and McCarthy conclude that, "the most important determinants of the performance of transit systems have remained relatively unchanged over time and across systems.”

As a result of this well-documented effort to identify key indicators of transit performance, we can be confident that any attempt to quantify transit performance in a similar manner is well grounded in the literature. This prior research establishes a sound theoretical and empirical basis for further work in evaluating the effects of organizational structure on performance. 


\section{Methodology, Analysis and Findings}

\subsection{INTRODUCTION}

3.2 FOCUS AND APPROACH
It is important to refresh the readers' mind that structure in this study is defined in the context of organizational form and management. That is, we have identified transit organizational structure as having four basic forms that are primarily characterized by ownership and type of management. Local governments own public transit systems in the United States but they are not all managed by their municipal or county governments. They range from being fully owned and managed by a local government to being owned by, but not managed by, a local government. The latter are generally referred to as public/private (or semi-government) management types, among which are several variations. These are properly defined as publicly owned but autonomous transit agencies. For the purpose of this study, however, we have categorized public transit systems as:

General government/public management (GGPM); i.e. agencies that are part of municipal governments (e.g. Miami-Dade Transit Agency).

- General Government/contract management (GGCM) i.e. agencies that are part of municipal governments but contract our their management functions (e.g. Escambia County Transit in Pensacola, FL.)

$\square$ Special Authority/public management (SAPM). i.e. transit agencies that, while publicly owned are autonomous entities in the public sector (e.g. San Diego Transit Corp).

- Special Authority/contract management (SACM) i.e. they are similar to SAPMs, but contract out their management functions (e.g. Ashville, North Carolina Transit Authority).

Specific to Florida, and most other states, these designations are indeed accurate, but it is important to point out that in Florida, no SACMs exist. (See Table 1).

The focus of this section of the study is to answer the question of whether the structure ascribed to a particular transit agency is a predictor of the performance of that agency. As the literature review in Section 2 of this study points out there have been ongoing studies to ascertain whether a relationship does exist between structure and performance but the judgment as to whether there is an easily discernable one is yet to be determined. What seems clear, though, is that continual research is needed in this area since the prospect for a conclusive answer lies in the probability of continual research. This research on transit system structures and their impact on performance joins the quest for more definitive answers. 
This study adopted qualitative and quantitative techniques to perform the analysis. The logic governing the combination of both qualitative and quantitative approaches is that qualitatively, the researchers wanted to examine the subjective or non-quantitative aspects of organizational structure and operations within the transit industry to better understand the nature (organization and operation) of the industry being studied. In effect, this approach was a special form of a pretest to see whether there was value in engaging in a rigorous quantitative analysis for determining more precisely what kinds of statistical relationships existed between structure and performance. A better understanding, we believe, could inform public policy making in the transit industry as to how to improve performance in areas deserving of improvement and where appropriate, recommend change in existing structural relationships.

One way of pursuing a statistical probe into the industry was to develop a survey instrument that would enable the study to determine, based on responses, whether there was a need to conduct a quantitative analysis. The research team also wished to determine whether there might be some areas that quantitative analysis may be limited in its ability to answer relevant research questions through the use of numerical values obtained from the National Transit Database (NTD). The research team recognizes that there are "micro-structure level" issues of management that numerical values may not be able to adequately explain yet finding explanations from such issues can shed light on the relationship between structure and performance in transit systems. In hind sight we were well justified in conducting both qualitative and quantitative studies and both have served well the objectives of this research project. In this section we analyze and discuss the findings of the qualitative data. In the following section of this study we provide an indepth discussion and analysis of the quantitative data. A synthesis of both qualitative and the quantitative findings is provided in the final section of this report.

\subsection{QUALITATIVE ANALYSIS}

As the literature review has demonstrated the term 'structure' is broadly defined, yet for purposes of this study a generally accepted and widely used definition of structure is: an entity made up of more or less interdependent elements and having a definite organizational pattern (Johansson, 1997). From a qualitative perspective, structure goes beyond the elements (vehicles, personnel, performance measures etc.) that make up the transit industry. Structure embodies constructs such as rules and regulations that govern the operation of the industry. These involve fiscal, financial, environmental and other guidelines, government interaction with transit agencies, managerial skills of transit managers, the provision of services such as 
training, healthcare, daycare centers and security for employees and support staff. All of these constructs and their interdependencies can jointly determine the performance of transit agencies.

3.4 SAMPLE

3.5 RESULTS AND DISCUSSION
As mentioned previously, the purpose of the qualitative analysis was to provide a broad understanding of the national transit industry as well as capture some of the variables that could contribute to the performance or lack of performance of transit agencies. Previous studies (Roethlisberger and Dickson:1938; Bennis in Kramer:1981; McKee:1983) have identified some of these as: worker dissatisfaction, inexperience of workers, rule violations, poor working conditions, just to name a few. Consequently, a survey instrument was developed to capture some of these variables in an effort to add depth to the study (see Appendix 2). The survey instrument targeted key variables that could provide relevant data indicative of the requirements for improvement in transit performance. A total of 120 questionnaires were mailed to randomly selected transit managers nationwide. Fifty three (53) percent of the agencies responded to the questionnaire. Their responses were coded then frequency tables were generated using SAS for Windows V. 8.2. The frequencies were used to develop an assessment platform for examining the current nature of the national transit system.

The first question that was designed to collect information on manager experience (see Table 3 ) showed that the largest group of respondents (30\%) had between 1 and 5 years experience with their agency. However, more than fifty percent of the managers surveyed had been with their agencies for 10 years or more years. This is indicated by the cumulative totals for the following categories: 10-15 yrs, 15-20 yrs and over $20 \mathrm{yrs}$ (Table 3). Although not a specific focus of this type of analysis, manager experience consistently has been hypothesized in other studies to be directly related to performance. In our study, even though respondents' comments on this question might be self-congratulatory, managers were clear in their minds that transit management experience had to be an important contributing factor to transit agency performance. As reminded by respondents, management is a critical component of all organizational structures given the fact that management involves, for example, policy formulation involving budgeting, human resource management (such as staffing), organization and coordination of agency units and functions, to name a few of the daily managerial roles of transit managers. In the management literature, experience of ten (10) years or more is considered to be considerable, and thus an asset to an agency with managers having that 
length of experience strongly suggests that experienced management can contribute positively to agency performance ${ }^{*}$.

TABLE 3. Distribution of managers with respect to years of experience

\begin{tabular}{lcccc}
\hline $\begin{array}{l}\text { Years of } \\
\text { Experience }\end{array}$ & Frequency & Percent & $\begin{array}{c}\text { Cumulative } \\
\text { Frequency }\end{array}$ & $\begin{array}{c}\text { Cumulative } \\
\text { Percent }\end{array}$ \\
$1-5$ & 19 & 29.69 & 19 & 29.69 \\
$5-10$ & 10 & 15.63 & 29 & 45.31 \\
$10-15$ & 12 & 18.75 & 41 & 64.06 \\
$15-20$ & 7 & 10.94 & 48 & 75.00 \\
$20+$ & 16 & 25.00 & 64 & 100.00 \\
Sample Size $=64$ & & & &
\end{tabular}

Believing that government interaction is a critical part of transit structural relationships we asked respondents about the level of their government interactions. Several respondents (about 54\%) commented that one's agency overall performance could be enhanced by the quality and scope of intergovernmental interaction between itself and other governments. The transit industry is replete with a host of intergovernmental forms of interaction from which a variety of benefits can be derived. Examples of these include fiscal, organizational, training and development, consolidation of services, and the like. By inference, managers were communicating the view that indeed there is a relationship between performance and assistance from all governmental levels including their own. The findings suggest that a significant amount of interaction takes place among transit systems at the local level (64\%). This does not mean that interaction with other levels does not occur; it is that most of the interaction takes place at that level (see Table 2). This group is significantly larger than those that imply that their interaction is mostly with other levels of government or who have little or no government interaction whatsoever. The findings illustrated in this table also highlight a fundamental reality about public transit in America: it is first and foremost a local government function.

* Intuitively, at least, one would assume that if experience is a key but not the only determinant of competent performance, then the greater the number of years an individual employs on a task, the greater the probability of increased performance, assuming other related factors such as continuing training, relevant retooling, etc have their intended effects on performance as well. As in every other aspect of life, diminishing marginal returns set in and thus after a number of years of experience, experience as a contributor to increased performance begins to decline. The literature on organizational humanism and general management theory, at least, infers a relationship between tenure and performance. The study sheds more light on management in the quantitative analysis that follows this section. 
Local governments, as Appendix 1 clearly demonstrates, own and manage an overwhelming number of these systems. They learn from each other, share information on their pains (and whatever gains) with each other, and lobby together through their various state transit associations their state and the federal government for various kinds of assistance. Indeed, the political and administrative obligations assigned to local governments by their state governments come with a built-in necessity for governmental interaction, if they are to survive, if not thrive.

When structure is defined as the type of institutions that make up the industry and the level of interaction between the agencies and institutions within the industry, the performance of agencies may be directly related to the type of government with which the agency interacts. Tables 4 through 7 give a breakdown of the agencies with respect to their government affiliations, taxing authority and management.

TABLE 4. Distribution of agencies with respect to govt. interaction

\begin{tabular}{|c|c|c|c|c|}
\hline Govt. & Frequency & Percdnt & $\begin{array}{l}\text { Cumulative } \\
\text { Frequency }\end{array}$ & $\begin{array}{c}\text { Cumulative } \\
\text { Percent }\end{array}$ \\
\hline Local & 41 & 64.06 & 41 & 64.06 \\
\hline State & 14 & 21.88 & 55 & 85.94 \\
\hline Federal & 6 & 9.38 & 61 & 95.31 \\
\hline $\mathrm{NGOs}^{*}$ & 3 & 4.69 & 64 & 100.00 \\
\hline \multicolumn{5}{|c|}{${ }^{*}=$ Non-profit organizations } \\
\hline \multicolumn{5}{|c|}{ Sample Size $=64$} \\
\hline $\begin{array}{r}\text { Note: inte } \\
\text { only, n } \\
\text { ing on }\end{array}$ & $\begin{array}{l}\text { orted by the } 41 \\
\text { encies interact } \\
\text { which most of }\end{array}$ & $\begin{array}{l}\text { encies does } \\
\text { only with st } \\
\text { r interactio }\end{array}$ & $\begin{array}{l}\text { timply interactio } \\
\text { agencies. Respon } \\
\text { ccurred. }\end{array}$ & $\begin{array}{l}\text { ith local level } \\
\text { ats were inform- }\end{array}$ \\
\hline
\end{tabular}

TABLE 5. Distribution of agencies by type

\begin{tabular}{|c|c|c|c|c|}
\hline Agency Type & Frequency & Percent & $\begin{array}{l}\text { Cumulative } \\
\text { Frequency }\end{array}$ & $\begin{array}{c}\text { Cumulative } \\
\text { Percent }\end{array}$ \\
\hline $\begin{array}{l}\text { Municipal } \\
\text { Govt. }\end{array}$ & 27 & 42.19 & 27 & 42.19 \\
\hline $\begin{array}{l}\text { Independent } \\
\text { Authority }\end{array}$ & 26 & 40.63 & 53 & 82.81 \\
\hline Other & 11 & 17.19 & 64 & 100.00 \\
\hline None & 52 & 81.25 & 52 & 81.25 \\
\hline Independent & 12 & 18.75 & 64 & 100.00 \\
\hline
\end{tabular}


TABLE 6. Distribution of transit managers by employment

\begin{tabular}{|c|c|c|c|c|}
\hline Employer & Frequency & Percent & $\begin{array}{l}\text { Cumulative } \\
\text { Frequency }\end{array}$ & $\begin{array}{c}\text { Cumulative } \\
\text { Percent }\end{array}$ \\
\hline Municipal govt. & 27 & 42.19 & 27 & 42.19 \\
\hline $\begin{array}{l}\text { Private mgmt. } \\
\text { company }\end{array}$ & 13 & 20.31 & 40 & 62.50 \\
\hline Other & 24 & 37.50 & 64 & 100.00 \\
\hline
\end{tabular}

When asked about their opinions with regard to the quality of their interaction with government agencies, half the number of the respondents thought that their interaction with government agencies was excellent. However an identical number thought that though acceptable, their interaction with government agencies could be improved (Table 7). The opinions of these two categories of agencies differed significantly to the three (3) percent of the agencies that claimed that their interaction with government agencies was poor. Generally, most transit agencies seem satisfied with their interaction with government agencies. Considering the diverse definitions of structure that include the interrelationships between government and agency, these findings provide encouraging implications that performance could be improved through improved government interaction/relations.

TABLE 7. Managers opinion regarding quality of govt. interaction

\begin{tabular}{lcccc}
\hline Quality & Frequency & Percent & $\begin{array}{c}\text { Cumulative } \\
\text { Frequency }\end{array}$ & $\begin{array}{c}\text { Cumulative } \\
\text { Percent }\end{array}$ \\
Excellent & 31 & 48.44 & 31 & 48.44 \\
Acceptable & 31 & 48.44 & 62 & 96.88 \\
Poor & 2 & 3.13 & 64 & 100.00 \\
Sample Size $=64$ & & & &
\end{tabular}

From a qualitative standpoint, the industry seems to be directed through fiscal/financial guidelines. A significant number of agencies (approximately $61 \%$ ) indicated that Fiscal/Financial guidelines were most effective in facilitating the effective provision of transit services (Table 8). To add strength to this finding, the second largest category of agencies (39\%) indicated that these same guidelines could prevent the effective provision of transit services if they were lacking (Table 9). It is evident, therefore, that the fiscal/financial factor (guidelines) could have quite a significant effect on the performance of transit agencies when properly structured. The 
findings and their implications are further discussed in the data synthesis section of this study.

TABLE 8. Mangers opinion on transit guidelines that effect performance

\begin{tabular}{|c|c|c|c|c|}
\hline Guideline & Frequency & Percent & $\begin{array}{l}\text { Cumulative } \\
\text { Frequency }\end{array}$ & $\begin{array}{c}\text { Cumulative } \\
\text { Percent }\end{array}$ \\
\hline Environmental & 2 & 3.13 & 2 & 3.13 \\
\hline Fiscal/Financial & 39 & 60.94 & 41 & 64.06 \\
\hline Land use statutes & 8 & 12.50 & 49 & 76.56 \\
\hline Economic & 6 & 9.38 & 55 & 85.94 \\
\hline Other & 9 & 14.06 & 64 & 100.00 \\
\hline \multicolumn{5}{|l|}{ Sample Size $=64$} \\
\hline \multicolumn{5}{|c|}{$\begin{array}{l}\text { TABLE 9. Mangers opinion on transit guidelines that hinder } \\
\text { performance }\end{array}$} \\
\hline Guideline & Frequency & Percent & $\begin{array}{l}\text { Cumulative } \\
\text { Frequency }\end{array}$ & $\begin{array}{l}\text { Cumulative } \\
\text { Percent }\end{array}$ \\
\hline Environmental & 9 & 14.06 & 9 & 14.06 \\
\hline Fiscal/Financial & 25 & 39.06 & 34 & 53.13 \\
\hline Land use statutes & 10 & 15.63 & 44 & 68.75 \\
\hline Economic & 7 & 10.94 & 51 & 79.69 \\
\hline Other & 13 & 20.31 & 64 & 100.00 \\
\hline
\end{tabular}

The rules and guidelines that direct the industry are important to the industry's performance. The majority of agencies (48\%) believe that they are budget recipients of last resort and therefore experience minimal efficiency in operations and service delivery. This re-asserts the necessity for not just strong government interaction but also strong fiscal/financial guidelines, which appear to be the driving force behind agency performance (Table 10). Many transit managers also believe that decision rules do not allow for enough creativity and individual judgment. Perhaps if managers had a greater input in drafting the guidelines under which their agency operated, efficiency in operation would be achieved. Their desire to have a greater input in decision-making is illustrated in (Table 11) where the two largest categories indicated that the rules should be either significantly changed or reformed. Only $6 \%$ of the managers surveyed felt that rules (for instance, respondents indicated selected land use regulations and 
unfounded mandates) should be discontinued and 3\% were not sure about what action(s) should be taken. However, the latter two categories were considerably smaller than the ones who felt that changes in the current guidelines were necessary. One may infer from this finding that proper decision rules can have a positive effect on agency performance.

\begin{tabular}{|c|c|c|c|c|}
\hline $\begin{array}{l}\text { Rules/ } \\
\text { Guideline }\end{array}$ & Frequency & Percent & $\begin{array}{l}\text { Cumulative } \\
\text { Frequency }\end{array}$ & $\begin{array}{c}\text { Cumulative } \\
\text { Percent }\end{array}$ \\
\hline 1 & 22 & 34.38 & 22 & 34.38 \\
\hline 2 & 3 & 4.69 & 25 & 39.06 \\
\hline 3 & 8 & 12.50 & 33 & 51.56 \\
\hline 4 & 31 & 48.44 & 64 & 100.00 \\
\hline \multicolumn{5}{|c|}{ Sample Size $=64$} \\
\hline \multicolumn{5}{|c|}{$1=$ Decision rules do not allow for enough creativity and individual judgment } \\
\hline \multicolumn{5}{|c|}{$\begin{array}{l}2=\text { Rules are too broad and do not give individual agencies enough guidance for indepen- } \\
\text { dent action }\end{array}$} \\
\hline \multicolumn{5}{|c|}{$3=$ Decision rules are always changing and do not give enough time for observable results } \\
\hline \multicolumn{5}{|c|}{$\begin{array}{l}4=\text { Transit agencies are budget recipients of last resort and therefore experience minimal } \\
\text { efficiency in operations and service delivery }\end{array}$} \\
\hline
\end{tabular}

TABLE 11. Mangers opinion with respect to changes in decision rules \& guidelines

\begin{tabular}{lcccc}
\hline Action & Frequency & Percent & $\begin{array}{c}\text { Cumulative } \\
\text { Frequency }\end{array}$ & $\begin{array}{c}\text { Cumulative } \\
\text { Percent }\end{array}$ \\
$\begin{array}{l}\text { Significantly } \\
\text { changed }\end{array}$ & 25 & 39.06 & 25 & 39.06 \\
$\begin{array}{l}\text { Continued } \\
\text { w/reform }\end{array}$ & 33 & 51.56 & 58 & 90.63 \\
$\begin{array}{l}\text { Discontinued } \\
\text { Not Sure }\end{array}$ & 4 & 6.25 & 62 & 96.88 \\
Sample Size $=64$ & 2 & 3.13 & 64 & 100.00
\end{tabular}

For decades, researchers have been concerned with the job satisfactionjob performance relationship. The underlying assumption has always been that a happy worker is a productive worker. It has already been asserted that continuous training of managers, supervisors and staff and the provision of community-oriented facilities such as: daycare centers, health care facilities, job placement centers, or employee security, can be instrumental 
to the performance of any industry. A greater proportion of the agencies surveyed ( $56 \%$ vs. $44 \%$ ) provide training for their staff on a frequent basis (Table 12). However, the difference between the two categories is still relatively small. Research has shown that when training and other amenities are provided for workers, their overall performance improves. In this case, it may be considered alarming that a significant number of agencies (72\%) have not contributed to or actively supported the development of nearby community-oriented facilities such as: daycare centers, health care facilities, job placement centers, or police substations (Table 13). This may be a negative aspect of their structure that could impede performance. For those agencies that did provide community-oriented facilities, day-care centers and police substations were the most prevalent (Table 14). When asked whether or not providing these facilities resulted in a more positive attitude by employees toward their agency, a large number of transit managers $(68 \%)$ indicated that they had seen an improvement in attitudes towards the agency (Table 15). This supports growing conventional view that the provision of community-oriented services should be a major component of transit agencies' structure as they could facilitate agency performance.

TABLE 12. Distribution of agencies with respect to the frequency of training for their staff

\begin{tabular}{lllll}
\hline Training & Frequency & Percent & $\begin{array}{c}\text { Cumulative } \\
\text { Frequency }\end{array}$ & $\begin{array}{c}\text { Cumulative } \\
\text { Percent }\end{array}$ \\
Frequently & 36 & 56.25 & 36 & 56.25 \\
Infrequently & 28 & 43.75 & 64 & 100.00 \\
Sample Size $=64$ & & & &
\end{tabular}

TABLE 13. Distribution of agencies with respect to the provision of community-oriented facilities

\begin{tabular}{lcccc}
\hline Facilities & Frequency & Percent & $\begin{array}{c}\text { Cumulative } \\
\text { Frequency }\end{array}$ & $\begin{array}{c}\text { Cumulative } \\
\text { Percent }\end{array}$ \\
No & 46 & 71.88 & 46 & 71.88 \\
Yes & 18 & 28.13 & 64 & 100.00 \\
Sample Size $=64$ & & & &
\end{tabular}


TABLE 14. Breakdown of community-oriented facilities provided by transit agencies for their workers

\begin{tabular}{lcccc}
\hline Facility & Frequency & Percent & $\begin{array}{c}\text { Cumulative } \\
\text { Frequency }\end{array}$ & $\begin{array}{c}\text { Cumulative } \\
\text { Percent }\end{array}$ \\
$\begin{array}{l}\text { Day-care } \\
\text { centers }\end{array}$ & 8 & 44.44 & 8 & 44.44 \\
$\begin{array}{l}\text { Health-care } \\
\text { facilities }\end{array}$ & 3 & 16.67 & 11 & 61.11 \\
$\begin{array}{l}\text { Police } \\
\text { substations }\end{array}$ & 5 & 27.78 & 16 & 88.89 \\
$\begin{array}{l}\text { Job place- } \\
\text { ment centers }\end{array}$ & 1 & 5.56 & 17 & 94.44 \\
$\begin{array}{l}\text { Other } \\
\text { Sample Size }=18\end{array}$ & 1 & 5.56 & 18 & 100.00
\end{tabular}

TABLE 15. Workers attitude towards the agency after the provision of community-oriented facilities

\begin{tabular}{lcccc}
\hline Improved & & & Cumulative & Cumulative \\
Atttitude? & Frequency & Percent & Frequency & $\begin{array}{c}\text { Percent } \\
\text { Not Sure }\end{array}$ \\
No & 5 & 22.73 & 5 & 22.73 \\
Yes & 15 & 9.09 & 7 & 31.82 \\
Sample Size $=18$ & & 68.18 & 22 & 100.00
\end{tabular}

3.6 CONCLUSIONS FROM THE SURVEY ON QUALITATIVE FACTORS AFFECTING PERFORMANCE
Experienced managers currently manage most of the transit agencies. Most of the agencies surveyed indicated a high level of experience on the part of their management and staff. Although manager experience is generally expected to be directly related to performance, survey results indicate an even stronger view among respondents that improved funding and greater flexibility in fiscal/financial guidelines can be very effective in boosting agency performance. Most transit managers believe that transit agencies are not given priority in government budgets. An analysis of the data, clearly indicate managers' understanding and appreciation of the role of funding and the fiscal guidelines associated with non-dedicated funding from different levels of government. This recognition of the importance of funding was even expressed when a majority of transit managers communicated the view that their agencies are budget recipients of last resort and, therefore, experience minimal efficiency in operations and service delivery. This is an indirect way of acknowledging the positive influence that 
intergovernmental funding has on transit performance among transit agencies.

Other factors that could enhance performance include the provision of community-oriented facilities such as health care and day-care centers for employees. A majority of the managers whose agencies provided these benefits indicated that they have seen an improvement in attitudes toward their agency. Research has shown that satisfied workers tend to be more productive. Performance could therefore be improved through the provision of training, health care and other benefits to workers.

In sum, these findings indicate that the study of the effect of structure on performance goes beyond structural forms (e.g. general government v. special authority) but that there are micro-structural variables that ought to be recognized for their impact on performance. Other studies (e.g. Hague, 1984) focused quite heavily on structural features with regard to other independent variables taken into consideration. Even though this study's focus is admittedly the effect of structural forms and management as affecting performance the research acknowledges other factors as illustrated in the results of the qualitative study.

It is appropriate, however, to identify those structures and their impact on various performance measures and to properly do so the study has employed the statistical technique known as Analysis of Variance (ANOVA). The following section provides a discussion on the quantitative analysis. 


\section{Quantitative Analysis And Findings}

4.1 INTRODUCTION.
Data for the independent variables to be used in the study's quantitative analysis were obtained from national transit database (NTD) files, as well as from the FDOT FTIS database and the ICMA 2000 municipal Year Book. A cursory review of available data sources informed us that because of incomplete or missing data we should anticipate a reduction in our usable sample size. As it turned out our sample was limited to approximately 212 agencies nationwide.

The only data that were not readily available for our quantitative study were the actual information on management and organizational structure. This data were obtained directly from transit agencies and state Departments of Transportation through phone interviews and mail surveys. The survey consisted of three simple questions related to the management and organizational structure of the agency. The questions were designed to elicit the following information:

Question 1: How is the transit agency organized? Is it

A. Part of a larger municipal government

B. A special authority or independent authority.

Question 2: If the answer is "B" there will be a follow up question:

A. Does the agency have taxing authority?

Question 3: Which ever is the organizational form of transit agency, Are the upper level managers of the agency employed by:
A. a municipal/county government
B. a special authority/independent authority, or
C. by contract management.

At every step we made certain that the meaning of key terms were quite clear or well understood by the interviewee.

The transit industry is understandably interested in the relationship between the structure of a transit agency and its performance. Our goal has been to identify a way to evaluate agency structure and examine its relationship to performance. Using quantitative analysis of available transit data we were able to empirically study this relationship. 
To construct an appropriate study, it was necessary to specifically define those elements of transit structure that we wished to examine, especially since "structure" is a very broad term and the structure of a transit agency has many dimensions.

Furthermore, many important elements of transit agency organization and management do not lend themselves easily to quantitative analysis. These have not been ignored in our research and were dealt with in our qualitative study. Nevertheless, we have identified several easily measurable aspects of transit agency organization and management that are useful in our study of performance. These are discussed in the ownership/management context of structure. They are categorized as independent and dependent variables.

\section{INDEPENDENT VARIABLES: ORGANIZATIONAL AND MANAGEMENT STRUCTURE.}

Organizational Structure. As discussed in the literature review of this study, transit agencies can be divided according to ownership and management. Local transit agencies can be classified into four groups, i.e. general government/public management; general government/contract management, special authority/public management and special authority/contract management. These four forms represent our structural characteristics or features of the independent variable, "structure."

Organizational Management. This is defined as personnel within transit organizations. Management personnel are those who have policy formulation, determination and implementation responsibilities. They are either appointed to serve at the pleasure of elected officials or career civil servants. Their ultimate responsibility is to ensure effective and efficient delivery of transit service to citizens.

In principle, transit agency personnel can be assigned to any one of the four basic groups, previously identified (GGPM, GGCM, SAPM, SACM). For instance management personnel can be employees of general government [GG] (city/county government); they can be non-governmental employees [GGCM, or SAPM] (i.e. outside the civil service system), or they can be employees of private sector management companies (SACM).

It is an entirely plausible premise that different management arrangements can have consequences for transit performance. For instance, contract management companies and civil servants may have different objectives, 
different levels of transit management experience, different levels of government administration experience, and different areas of expertise. We therefore expect organizational management as an independent variable to contribute to our understanding of the relationship between structure and performance.

\section{ANALYSIS}

The focus of this section of the study is to answer the question of whether transit agencies that conform to a particular structure perform better when compared to transit agencies that conform to other types of structure. In order to determine this, we focused on certain dimensions of organizational structure that have traditionally been used as performance indicators.

\section{SELECTING THE BEST PERFORMANCE MEASURES (DEPENDENT VARIABLES)}

While public transit professionals often have more than forty measures of general performance, efficiency, and effectiveness to choose from, this research project was careful to select those measures that convey the most information about different aspects of transit service. Bearing that in mind, we focused on eleven different measures of performance.

Successful service provision is often defined in terms of "efficiency", where "efficiency" is measured as output relative to the costs of production. This definition is used frequently in the transit literature, but researchers are often interested in documenting a much broader category of "performance". Performance is a term that incorporates many possible dimensions, however, and documenting the elusive goal of performance is an issue that researchers have been refining for decades.

An early exposition of the issue is provided in Productivity, Efficiency, and Quality in Urban Transportation Systems by Tomazinis (1975). Even after extensive simplification, the author comes up with an extensive collection of measurements to document performance. He identified five important areas of interest - unit costs, input of resources, relative distribution of costs, provision of service, and collection of revenue - and noted that each one can be measured with a variety of ratios. Altogether, Tomazinis provides no fewer then twenty-seven different "analytically significant" measures to evaluate the efficiency of transit provision from the point of view of the providers. Fourteen additional measures are provided to document 
what Tomazinis calls "effectiveness indicators" for transit users. Because of the difficulties presented by using such a wide variety of measures, much of the literature in the intervening years has struggled to pare down the number of transit performance measures to a more manageable set.

Talley and Becker (1982) pushed their research to the other extreme, attempting to distill transit performance into a single measure. They draw a parallel with cost-minimizing firms in the private sector and suggested that maximum transit agency effectiveness is achieved when the agency minimizes cost for a given level of ridership. The authors further argued that the transit route should be used for the unit of analysis, and that the "transit deficit per passenger" (that is, revenue minus expenditures divided by the number of passengers) is the one appropriate measure of the success of a route. They assert that this is a superior measure of transit success because it includes both cost ratios (which capture "efficiency") and numbers of passengers (which capture "effectiveness").

The significant drawback of this approach is that the multifaceted nature of transit service provision may not be captured in one single variable, but must be evaluated systematically with a set of carefully designed measures. Benjamin and Obeng (1990) stated the problem quite succinctly: "The need for performance measures has led to the development of a large number of ad hoc measures of productivity, efficiency, and effectiveness." Their approach focused on "total factor productivity" as a measure of performance. Their study measured output in terms of passenger miles and vehicle miles, and input in terms of labor operating cost, fuel price, and number of vehicles. This work succeeded in maintaining a small number of measurements, but at the cost of eliminating important information about effectiveness.

A compromise or synthesis began emerging in Fielding, Babitsky, and Brenner (1985) who systematically defined the nature of transit performance. Starting with nearly fifty different performance indicators, the authors used extensive analysis to determine which measures were "key" indicators of performance. Using Section 15 (NTD) transit data, they identified seven indicators that represented what they called "the key underlying dimensions of performance": revenue vehicle hours per operating expense, unlinked passenger trips per revenue vehicle hour, operating revenue per operating expense, vehicle hours per employee, vehicle miles per peak vehicle required, vehicle miles per maintenance employee, and millions of vehicle miles per accident is used as a measure of safety. 
More recently, Karlaftis and McCarthy (1997) used the more rigorous technique of factor analysis to define a small set of performance measures. Using terminology similar to Cervero they defined three "factors" or dimensions of performance: overall performance (which captures revenues and costs), efficiency (which captures cost efficiency as well as labor and vehicle utilization), and effectiveness (which captures service and accessibility). Each of these performance dimensions is correlated with the others, but each provides a distinct contribution to the evaluation of system performance. The authors used factor analysis to identify indicators that can best explain or account for each of the factors. The result was a model in which the following indicators are used to quantify each factor

\section{OVERALL PERFORMANCE}

$\square$ Ratio of operating revenue to operating cost

$\square$ Passengers per operating expenses

\section{EFFECTIVENESS}

$\square$ Passengers per capita

$\square$ Passengers per vehicle

$\square$ Passengers per revenue vehicle mile

\section{EFFICIENCY}

$\square$ Revenue vehicle miles per employee

$\square$ Revenue vehicle miles per vehicle

$\square$ Revenue vehicle miles per operating expense

Interestingly, these indicators are very similar to those identified more than a decade earlier by Fielding, Babitsky, and Brenner. Karlaftis and McCarthy conclude that, "the most important determinants of the performance of transit systems have remained relatively unchanged over time and across systems.”

From this collection we have selected eleven measures that are readily available or could be readily calculated from the National Transit Database (NTD). The measures are grouped into two categories: Efficiency Measures and Effectiveness Measures. In keeping with standard practice in the transit industry, we make a distinction between performance measures that contain a measure of ridership and those that do not. They are as follows: 


\section{EFFICIENCY MEASURES}

$\square$ Operating expense per revenue hour

- Total operating revenue per operating expense

$\square$ Vehicle miles per peak vehicle

$\square$ Annual vehicle miles per maintenance employee

$\square$ Revenue miles between incidents

$\square$ Revenue vehicle miles per employee

\section{EFFECTIVENESS MEASURES}

$\square$ Unlinked passenger trips per revenue hour

Unlinked passenger trips per operating expenses

- Unlinked passenger trips per capita

Unlinked passenger trips per revenue vehicle mile

4.2 DETAILS OF STATISTICAL ANALYSIS
Using the Statistical Analysis System (SAS version 8.2) we performed Analysis of Variance (ANOVA) to test for significant differences between the mean performance measures, as they relate to the different forms of structure. For the dependent variables we used the 10 performance measures discussed above. For independent variables we used the ownership/ management forms and ownership-management combinations (structural forms) illustrated in the literature. All 10 dependent variables are for the year 2000 and were obtained directly from the Federal Transit Administration (2002) National Transit Data Base 2000 Data Tables and the FDOT (2001) Florida Transit Information System.

Variable names use standard transit industry terminology. While we were able to collect data on management and organizational structure from two hundred and eleven transit agencies from the National Transit Database, we encountered some level of difficulty in obtaining complete data on some independent variables as the National Transit Database has missing data on these variables. Because of this, the sample sizes for the four structural forms ranged from 13 to 90 depending primarily on how many agencies reported data for the dependent variables. Sample sizes for the two forms of management ranged from 42 to 161 . Bearing in mind the unbalanced nature of the data, the General Linear Models (GLM) procedure of ANOVA was employed to validate this situation.

To test the hypothesis of equality between means, Fisher's Least Significant Difference (LSD) test was applied. Fisher's LSD can be computed easily in 
SAS. Those pairs of means for which the difference is greater than LSD in magnitude are significantly different at the alpha level (0.05) chosen for the test. Mean comparisons are reported in the tables that follow the results and discussion. Typically, Fisher's LSD is only applied after the ANOVA has indicated evidence of significant differences between at least two means. However, we applied it nevertheless since it would provide the least difference between the means that would be required to make their difference in performance significant.

4.3 HYPOTHESES AND DATA ANALYSIS
As mentioned earlier, the focus of this section of the study was to answer the question of whether transit agencies that conform to a particular structure performed better when compared to transit agencies that conform to other types of structure. Traditionally, transit structures are categorized on the basis of type of ownership and type of management. When management is defined in terms of personnel not related to ownership, it is necessary (sometimes because of policy implications) to determine whether different forms of management have significant effects on transit performance. Evaluating management as a component of structure is important since this allows researchers to more carefully examine the performance effects due to management and not confuse them with effects due to ownership. Using quantitative analysis of available transit data we were able to empirically demonstrate this. This study tested the effects of ownership, management and ownership-management combinations on transit agency performance. Presenting organizational structure and organizational management in this way, allowed us to test three separate hypotheses:

1. After controlling for demographic and other variables, fully publicly owned agencies do not perform significantly better compared to special authorities. That is:

$$
\mu_{1}=\mu_{2}
$$

Where: $\mu_{1}=$ The mean for a specific performance measure observed for publicly owned agencies and $\mu_{2}=$ The mean for a specific performance measure for authorities.

2. After controlling for demographic and other variables, publicly managed agencies do not perform significantly better compared to contract-managed agencies. That is:

$$
\mu_{3}=\mu_{4}
$$


Where: $\mu_{3}=$ The mean for a specific performance measure observed for publicly managed agencies and $\mu_{4}=$ The mean for a specific performance measure for contract managed agencies.

Drawing from the different forms of transit ownership and management outlined in the literature review, four general forms of ownership-management combinations (structures) were made possible. These are:

1. General Government/Publicly Managed (GGPM)

2. General Government/Contract Managed (GGCM)

3. Special Authority/Publicly Managed (SAPM)

4. Special Authority/Contract Managed (SACM)

In this case then, the third hypothesis tested was:

3. After controlling for demographic and other variables, there will be no significant difference in performance between the four ownershipmanagement combinations that define the transit agency structures covered in the literature. That is:

$$
\mu_{1}=\mu_{2}=\mu_{3}=\mu_{4}
$$

In conceptual form, a model depicting the dependency of performance on structure can be expressed as follows:

$\mathrm{PER}_{\mathrm{it}}=\mathrm{f}(\alpha, \phi, \alpha \phi) \quad$ (Equation 1$)$

Where:

$\mathrm{PER}_{\mathrm{It}}=$ The performance observed for the the $\mathrm{i}^{\text {th }}$ performance measure in time period $\mathrm{t}(\mathrm{t}=$ the year 2000$)$ and $(\mathrm{i}=$ performance measures 1 to 10$)$

$\alpha=$ Agencies that conform to a particular type of ownership ( $\alpha=1$ to 2 ) i.e. Publicly owned or Special Authority.

$\phi=$ Agencies that conform to a particular type of management ( $\phi=1$ to 2$)$ ie. Public or Contract Management.

$\alpha \phi=$ A specific Ownership-Management combination that defines a particular transit agency structure. ( $\alpha \phi=1$ to 4$)$ i.e. GGPM, GGCM, SAPM and SACM 
GGPM = Agencies that conform to the General Government Public Management structure

GGCM = Agencies that conform to the General Government Contract Management structure

SAPM $=$ Agencies that conform to the Special Authority Public management structure and

SACM $=$ Agencies that conform to the Special Authority Contract management structure

With the conceptual model provided in equation 1 , it is possible to estimate the individual (main) effects of ownership and management as well as, their joint (interaction) effects without confounding their relative contributions to performance. As such, the empirical model used to estimate the effects of ownership, management and ownership-management combinations, was specified as follows:

$\mathrm{PER}_{\mathrm{it}}=\beta+\alpha_{\mathrm{i}}+\phi_{\mathrm{j}}+\alpha_{\mathrm{i}} \phi_{\mathrm{j}}+\mathrm{E}_{\mathrm{ij}}$ (Equation 2)

Where:

$\mathrm{PER}_{\mathrm{it}}=$ The performance value observed for the $\mathrm{i}^{\text {th }}$ performance measure in time period $t,(t=$ the year 2000) and $(i=$ performance measures 1 to 10).

$\beta=A$ common effect for the overall experiment which is an unknown constant.

$\alpha_{i}=$ The mean performance value observed for the $i^{\text {th }}$ type of Ownership $(\mathrm{i}=1$ to 2$)$

$\phi_{j}=$ The mean performance value observed for the $\mathrm{j}^{\text {th }}$ form of management ( $\mathrm{j}=1$ to 2$)$

$\alpha \phi_{\mathrm{ij}}=$ An effect due to a specific ownership-management combination (ij $=4)$

and 
$E_{i j}=A$ random error term associated with the response from a specific type of ownership-management combination $i$ and $j$

This model is unique since it captures the individual (main) effects of ownership and management and also their joint effects as an individual structure comprised of ownership and management components. As indicated previously, this is important to avoid confounding the individual (main) effects of ownership, management and ownership-management combinations with each other. The effects of demographic and other variables exogenous to the model are captured by the error term associated with the model.

The hypotheses tested were that the $\alpha_{i}$ 's, $\phi_{j}$ 's and the $\alpha \phi_{i j}$ 's for the different types of ownership, management and ownership-management combinations (structures) respectively were not significantly different when compared to each other.

4.4 RESULTS OF ANALYSIS
Our findings with respect to the test of the first hypothesis of no significant differences in performance with regards to type of ownership are presented in Table 16. Generally, the special authorities performed better compared to agencies that are part of municipal governments. Special authorities had higher mean performance for 7 out of ten (70 percent) of the performance indicators evaluated. However, we failed to reject the null hypothesis of no significant difference in performance where type of ownership was concerned, since none of the mean performance differences were high enough to be considered significant at the 0.05 alpha level. Although none of the types of ownership demonstrated a clearly dominant trend, special authorities were more effective in 3 out of six efficiency indicators and all 4 of the effectiveness measures. However, as with the efficiency measures the gains in effectiveness attributed to special authority ownership were only marginal. 
TABLE 16. Effect of Type of Ownership on Performance Indicators

\begin{tabular}{|c|c|c|c|c|}
\hline \multirow[t]{2}{*}{$\begin{array}{l}\text { Performance } \\
\text { Indicators }\end{array}$} & \multicolumn{2}{|c|}{ Type of Ownership } & \multirow{2}{*}{$\begin{array}{l}\text { Performance } \\
\text { Difference } \\
(\mathrm{GG}-\mathrm{SA})\end{array}$} & \multirow{2}{*}{$\begin{array}{l}\text { Least Sig. } \\
\text { Difference } \\
\text { (LSD) }\end{array}$} \\
\hline & $\begin{array}{l}\text { GG } \\
(n=82)\end{array}$ & $\begin{array}{l}\text { SA } \\
(n=121)\end{array}$ & & \\
\hline OPERATIN & 61.98 & $63.98 \dagger$ & $-02.00 \mathrm{~ns}$ & 5.41 \\
\hline PASSENGE & 26.46 & $27.11 \dagger$ & $-00.65 \mathrm{~ns}$ & 3.35 \\
\hline MLBTWINC & $143640.00 \dagger$ & 102374.00 & $41266.00 \mathrm{~ns}$ & 42567.00 \\
\hline MILPERVE & $43.44 \dagger$ & 42.68 & $00.76 \mathrm{~ns}$ & 2.89 \\
\hline PASPEROP & 00.43 & $00.46 \dagger$ & $-00.03 \mathrm{~ns}$ & 0.07 \\
\hline PASPERCAP & 00.02 & $00.03 \dagger$ & $-00.01 \mathrm{~ns}$ & 0.02 \\
\hline MIPEREMP & 16.23 & $16.79 \dagger$ & $-00.56 \mathrm{~ns}$ & 3.22 \\
\hline PASPRMIL & 02.06 & $02.16 \dagger$ & $-00.10 \mathrm{~ns}$ & 0.36 \\
\hline OPRVOPEX & 01.35 & $01.36 \dagger$ & $-00.01 \mathrm{~ns}$ & 0.07 \\
\hline AVMEMP & $132.36 \dagger$ & 114.18 & $18.18 \mathrm{~ns}$ & 40.00 \\
\hline \multicolumn{5}{|c|}{$\dagger=$ Highest mean performance values } \\
\hline \multicolumn{5}{|c|}{$\mathrm{ns}=$ Not significant at the $0.05 \alpha$ level } \\
\hline \multicolumn{5}{|c|}{ Legend for performance measures indicators: } \\
\hline \multicolumn{5}{|c|}{ OPERATIN $=$ operating expense per revenue hour } \\
\hline \multicolumn{5}{|c|}{ PASSANGE $=$ passenger trips per revenue hour } \\
\hline \multicolumn{5}{|c|}{ MLBTwINC $=$ revenue miles between incidents } \\
\hline \multicolumn{5}{|c|}{ MILPERVE $=$ vehicle miles per peak vehicle } \\
\hline \multicolumn{5}{|c|}{ PASPEROP $=$ passenger trips per operating expense } \\
\hline \multicolumn{5}{|c|}{ PASPERCP $=$ unlinked passenger trips per capita } \\
\hline \multicolumn{5}{|c|}{ MIPEREMP $=$ revenue vehicle miles per employee } \\
\hline \multicolumn{5}{|c|}{ PASPRMIL = unlinked passenger trips per revenue vehicle mile } \\
\hline \multicolumn{5}{|c|}{ OPRVOPEX $=$ operating funds per operating expense } \\
\hline AVMemp $=$ annu & hicle miles & ntenc & & \\
\hline
\end{tabular}

In testing the second hypothesis, we sought to determine whether significant differences in performance could be attributed to type of management. As with the test for the effects of type of ownership, we failed to reject the null hypothesis of no significant difference between mean performance indicators with respect to type of management. However, although not significantly better, publicly managed agencies had higher mean performance indicators for 6 out of 10 (60 percent) of the performance measures. (See Table 17.) Publicly managed agencies also proved to be more efficient compared to contract-managed agencies. Contract managed agencies however were more effective in providing transit services as 
was evident in higher mean passenger trips per revenue hour, passenger trips per operating expense, passenger trips per revenue vehicle mile and in general, passengers per capita.

TABLE 17. Effect of Type of Management on Performance Indicators

\begin{tabular}{|c|c|c|c|c|}
\hline \multirow[t]{2}{*}{$\begin{array}{l}\text { Performance } \\
\text { Indicators }\end{array}$} & \multicolumn{2}{|c|}{ Type of Management } & \multirow{2}{*}{$\begin{array}{l}\text { Performance } \\
\text { Difference } \\
(\mathrm{GG}-\mathrm{SA})\end{array}$} & \multirow{2}{*}{$\begin{array}{l}\text { Least Sig. } \\
\text { Difference } \\
\text { (LSD) }\end{array}$} \\
\hline & $\begin{array}{l}\text { GCCM } \\
(n=161)\end{array}$ & $\begin{array}{l}\text { SACM } \\
(n=42)\end{array}$ & & \\
\hline OPERATIN & $64.11 \dagger$ & 59.47 & $04.64 \mathrm{~ns}$ & 6.62 \\
\hline PASSENGE & 26.82 & $26.89 \dagger$ & $-00.07 \mathrm{~ns}$ & 4.10 \\
\hline MLBTWINC & $123702.00 \dagger$ & 102226.00 & $13476.00 \mathrm{~ns}$ & 52067.00 \\
\hline MILPERVE & 42.85 & $43.54 \dagger$ & $-00.69 \mathrm{~ns}$ & 3.56 \\
\hline PASPEROP & 00.44 & $00.48 \dagger$ & $-00.04 \mathrm{~ns}$ & 0.09 \\
\hline PASPERCAP & $00.02 \dagger$ & 00.01 & $00.01 \mathrm{~ns}$ & 0.02 \\
\hline MIPEREMP & $16.86 \dagger$ & 15.30 & $01.56 \mathrm{~ns}$ & 3.98 \\
\hline PASPRMIL & 02.11 & $02.16 \dagger$ & $-00.05 \mathrm{~ns}$ & 0.44 \\
\hline OPRVOPEX & $01.39 \dagger$ & 01.22 & $00.17 \mathrm{~ns}$ & 0.21 \\
\hline AVMEMP & $124.72 \dagger$ & 109.19 & $15.53 \mathrm{~ns}$ & 49.00 \\
\hline
\end{tabular}

The results of the comparisons to determine significant differences in performance relative to type of structure are summarized in Table 18. As in the previous two cases, we failed to reject the hypothesis of no significant difference in performance between structures. None of the 4 structural forms displayed any significant performance patterns compared to the others. Independent authorities that were publicly managed proved to be more efficient compared to the other 3 types of structure achieving higher revenue vehicle miles per employee and maintaining a higher ratio of operating funds to operating expenses. They did however have the highest operating expenses per revenue hour. Publicly owned but contract-managed agencies were more effective in the provision of transit services. These agencies achieved more passenger trips per revenue hour, passenger trips per revenue vehicle mile and passengers per capita compared to the other structures. Publicly owned and managed and independent authorities with contract management performed poorly compared to the other two structures. Generally, the publicly managed independent authorities were more efficient whereas agencies that are part of municipal govern- 
ments and with contract management were more effective in providing transit services.

Overall, structure did a poor job of explaining performance. In all 10 models, structure explained no more than 5 percent of the variation in performance. The inability of structure by itself to explain variations in performance is supported by many previous studies (see Literature Review of this study) that sought to establish the structure-performance relationship. It appears then that more in-depth analysis will have to be done to account for variables that have greater explanatory power.

TABLE 18. Joint Effects of Ownership \& Management on Performance Indicators

\begin{tabular}{lcccc}
$\begin{array}{l}\text { Performance } \\
\text { Indicators }\end{array}$ & \multicolumn{5}{c}{ Ownership-Management Combinations } \\
& $\begin{array}{l}\text { GGPM } \\
(\mathbf{n = 6 9 )}\end{array}$ & $\begin{array}{l}\text { GGCM } \\
(\mathbf{n}=\mathbf{1 3})\end{array}$ & $\begin{array}{l}\text { SAPM } \\
(\mathbf{n}=\mathbf{9 0})\end{array}$ & $\begin{array}{l}\text { SACM } \\
(\mathbf{n}=\mathbf{3 1})\end{array}$ \\
OPERATIN & $62.40 \mathrm{a}$ & $59.62 \mathrm{a}$ & $64.96 \mathrm{a} \dagger$ & $61.20 \mathrm{a}$ \\
PASSENGE & $26.01 \mathrm{a}$ & $29.00 \mathrm{a} \dagger$ & $27.14 \mathrm{a}$ & $27.01 \mathrm{a}$ \\
MLBTWINC & $151657.00 \mathrm{a} \dagger$ & $86722.00 \mathrm{a}$ & $101335.00 \mathrm{a}$ & $105223.00 \mathrm{a}$ \\
MILPERVE & $43.75 \mathrm{a}$ & $41.60 \mathrm{a}$ & $42.19 \mathrm{a}$ & $44.13 \mathrm{a} \dagger$ \\
PASPEROP & $00.42 \mathrm{a}$ & $00.48 \mathrm{a}$ & $00.45 \mathrm{a}$ & $00.48 \mathrm{a} \dagger$ \\
PASPERCAP & $00.02 \mathrm{a}$ & $00.03 \mathrm{a} \dagger$ & $00.02 \mathrm{a}$ & $00.02 \mathrm{a}$ \\
MIPEREMP & $16.50 \mathrm{a}$ & $14.75 \mathrm{a}$ & $17.27 \mathrm{a} \dagger$ & $15.34 \mathrm{a}$ \\
PASPRMIL & $02.03 \mathrm{a}$ & $02.25 \mathrm{a} \dagger$ & $02.14 \mathrm{a}$ & $02.20 \mathrm{a}$ \\
OPRVOPEX & $01.35 \mathrm{a}$ & $01.33 \mathrm{a}$ & $01.42 \mathrm{a} \dagger$ & $01.17 \mathrm{a}$ \\
AVMEMP & $136.68 \mathrm{a} \dagger$ & $109.33 \mathrm{a}$ & $116.70 \mathrm{a}$ & $107.86 \mathrm{a}$ \\
Note: Row values represent mean performance measures \\
$\begin{array}{l}\dagger \\
\text { Row valuest mean }\end{array}$
\end{tabular}




\section{Summary, Data Synthesis and Conclusion}

5.1 SUMMARY

\subsection{SYNTHESIS}

The principal task of this study has been to determine how the structure of transit agencies affects their performance. To adequately do so it was necessary for the study to operationally define structure in a manner that allowed us to present three hypotheses and to test them on data obtained from the NTD and the ICMA Municipal Yearbook, 2000. Structure is defined as consisting of four different transit forms, each publicly owned, though the independent authorities are a special form of public ownership. The four structures, previously discussed are GGPM, GGCM, SAPM, SACM. Each is interwoven with one of two types of management namely, public management (PM) or contract management (CM). The previous three tables illustrate the relationships among different types of structures and 10 performance measures. The model did not provide the study with any conclusive answer to the question whether structure predicts performance. Although numerical differences were evident between structures, these differences were only marginal. Publicly managed independent authorities appear to be slightly more efficient in providing transit services compared to the others.

It appears from our work that there is no magic recipe for explaining the relationship between organizational structure and transit performance. Study after study as already referred to in the literature review seems unable to definitively provide researchers and transit policy makers and or practitioners with ready answers as to what it is that determines performance. Structure clearly by itself does not, as our study indicates. Management, when combined with structure is a bit more helpful in informing us about the relationship between structure and performance. We feel even more justified in our exploratory qualitative study for it recognized the difficulty that previous studies have encountered in attempting to arrive at conclusive answers about the relationship between structure and performance.

An important lesson to be drawn from this study is that public management can make the difference in structural forms, more so than ownership. Management is an expression of organizational behavior, or more precisely, behavior of individuals in organizations, values, goals, methods of implementation, outputs and outcomes. And often the consequences of these cannot always be picked up from databases, yearbook, or statistical abstracts. 
Policy makers however often wish to evaluate both the structure of transit agencies and the efficiency and effectiveness of their service delivery. It is this fact that also gives this study significance and thus could add value to public policy considerations. In its conclusion, the study identifies key findings that public policy makers may wish to consider as they inform themselves on public transit systems, particularly with regard to the relationship between structure and performance. The following are suggested considerations for transit policy makers:

1. Consideration of Structure. In the event that policy makers seriously wish to consider structural changes among transit agencies as a means to increase transit efficiency and effectiveness in service delivery, this study's findings suggest that the relationship between structure and performance is not sufficiently clear-cut and, therefore, caution and careful deliberation are advised. The NTD based data, as interpreted by our research team, do not adequately support the need for large-scale structural overhaul of transit agencies in Florida as well as in other states.

The qualitative data, at best, in its effort to ascertain whether micro-structural variables might better explain the relationship between structure and performance is not conclusive either. For example, longevity of managerial experience only infers that more experience probably results in increased performance. Thus, transit systems with long management tenure ${ }^{\star}$ (i.e. managers in positions over 10 years), such as in Miami, Tampa, Orlando or Los Angeles could be cited only as likely examples of management experience having a positive effect on agency performance. High level transit officials and policy makers who may wish to consider this micro-structural variable further could find some validity in doing so, given the inference made in this study.

The quantitative data used in this study could not quantify the relationship between structure and performance based on management experience. But by interviewing transit managers themselves as part of the qualitative part of the study, we were able to obtain a sense of the impact of management as one of the micro-level variables on performance. Results of the qualitative analysis, however, remind the transit industry in particular and other industries in general that management experience remains an

* Longevity in management does not necessarily mean the manager acquired all or more than 10 years in the same agency. An accumulation of ten years or more from employment in high-level positions at various transit agencies also fits the definition of "long tenure" in transit management. 
important consideration in personnel policy deliberations, and also an important ingredient in the determination of organizational performance.

2. Deciphering Which Management Form. Good management continually searches for increased efficiencies, that is, increased output per unit, at lower costs. Contract management or out-sourcing is still commonly adopted and implemented in the public sector. This study, however, has not found any statistical difference between one form of management or the other; that is, there is no significant difference between publicly managed transit agencies and contract management agencies. Indeed, for transit policy makers who wish to opt for increased contract management our research could not support that decision.

Policy makers, however, can be informed by the following specific findings of our study:

- Special (Independent) authorities perform better compared to agencies that are part of municipal governments. Our results show that these structures had a higher mean performance in 8 of 10 indicators.

- Statistically, however, there was no significant difference in performance where type of ownership was concerned.

$\square$ Agencies that are part of municipal governments proved to be more efficient compared to contract management agencies. They had a higher mean performance in 7 of 10 indicators.

- Contract management agencies, however, had a higher effectiveness mean performance than agencies that are part of municipal governments.

None of the four (4) structures we studied displayed (GGPM, GGCM, SAPM and SACM) any significant difference in performance. That is, statistically, none of the structures studied can be said to be superior in performance when compared to the others. At best, we can only say that according to our findings, some structures performed better in certain performance areas than in other areas or performance activities. ${ }^{*}$

\footnotetext{
* A higher mean in either of the efficiency or effectiveness indicators does not automatically translate into statistical significant difference, but the difference can and does indicate important differences depending on the degree of difference or variation between the mean of one type of structure compared to another.
} 
3. Status of Transit Funding. With regard to transit funding, we can rely on the results of the qualitative study, which clearly infer that funding is an important element of transit performance. This seems fairly obvious since funding in any endeavor invariably contributes to the effectiveness of organizational performance

Well over $80 \%$ of respondents commented that funding is critical to the effectiveness of transit operations. As reported earlier in this study (see qualitative analysis section) transit officials acknowledged the centrality of funding and also by almost the same percentage point felt that the effectiveness could be increased if many of the fiscal guidelines could be less "stifling" on transit agencies. In summary, these comments from respondents clearly infer that better fiscal guidelines are needed to ensure greater predictability and ease in funding flows to transit agencies. As one transit official remarked: "Money may be the mother's milk of politics, but it sure is the fuel in the tank of transit buses."

4. Customer Oriented Transit Systems. The qualitative data clearly infer that transit systems with a customer-oriented approach are likely to experience increased levels of effectiveness. The Hawthorne Studies (1924), research in workers' satisfaction, Maslow's (in Starling, 1986) hierarchy of needs, sociological research on the worker in the workplace, as well as research by industrial psychologists have overwhelmingly demonstrated the relationship between positive feelings in the workplace and output. Transit management response to workers needs for childcare assistance, employee security, commitment to work incentive schemes and the like, can indeed contribute to performance. The qualitative data suggest that as employees take advantage of these services or benefits workers are likely to express their satisfaction through increased levels of participation, which will likely translate into increased performance. Quantitative data could not easily demonstrate such positive effects on performance but again respondents' anecdotal comments have helped us to understand the micro-structural impact of this variable on performance. High-level transit officials and policy makers can be informed by these inferences from our qualitative data as they proceed to consider public transit policy issues.

\subsection{CONCLUSION}

This study has contributed to the expansion of the literature on the relationship between structure and performance. It however has also confirmed the need for continual research in this very difficult area of social science research. The complexity of this area of study occurs partly because of the multiplicity of social variables (some of which can be defined as micro-structural, such as agency incentives, values or goals, as 
highlighted in our qualitative study). Adding to the complexity is the complex variable of management itself, which we included in our quantitative analysis. The combination of quantifiable and non-quantifiable structural and managerial elements contributes to the continuing difficulty of clearly determining the precise relationship between structure and performance. Thus, therein lies a major reason why the results of the study's investigation on the relationship between structure and performance are mixed, at best. Structure is not just the physical combination of parts that respond to laws of nature or the logic of machines or equipment. Structure, like its counterpart, performance, is very involved with the interplay of human beings. Human beings are complex organisms and thus their behavior is complex. Results of such studies are often mixed, unless done over an extended period of time.

As a result, the researchers recognize the need for both qualitative and quantitative analyses to help find answers to questions that involve the interplay of physical structures and human behavior within those structures. Our above summary and synthesis provide information that we believe will serve as a useful guide to transit officials and operatives in their search for better structural arrangements and improved performance in the transit industry. Perhaps follow-up or longitudinal studies will help in presenting a clearer picture regarding a core relationship in public management, that is, the relationship between structure and performance.

\section{REFERENCES}

Anderson SH (1983) The Effect of Government Ownership and Subsidy on Performance: Evidence From the Bus Transit Industry. Transportation Research A 17A(3): 191200.

Benjamin J and Obeng K (1990) The Effect of Policy and Background Variables on Total Factor Productivity for Public Transit. Transportation Research 24B(1): 1-14.

Bierhanzl, E (1999) Incentives for Efficiency: User Charges and Municipal Spending, Journal of Public Finance and Public Choice, 17, 1.

Cervero R (1984) Cost and performance impacts of transit subsidy programs. Transportation Research A 18A(5/6), 407-413.

Deno KT and Mehay SL (1987) Municipal Management Structure and Fiscal Performance: Do City Managers Make a Difference? Southern Economic Journal, 53(3), 627-642.

Duffy-Deno KT and Dalenberg DR (1990) Do Institutions Matter? An Empirical Note, National Tax Journal, 43(2) 207-215.

Federal Transit Administration (2002) National Transit Database Data Tables 2000, http:// www.ntdprogram.com/NTD/NTDData.nsf/Data+Tables?OpenView

Fielding GJ, Babitsky TT \& Brenner ME (1985) Performance evaluation for bus transit. Transportation Research 19A(1), 73-82.

Fielding GJ, Glauthier RE, and Lave CA (1978) Performance Indicators for Transit Management. Transportation 7, 365-379. 


\section{Section 5. Summary, Data Synthesis and Conclusion}

Florida Department of Transportation (2001) Florida Transit Information System, Version 2001. CD-ROM. FIU.

Gillette, C. (1994) Public Authorities and Private Firms as Providers of Public Goods. RPPI Policy Study No. 180. Los Angeles: Reason Public Policy Institute.

Good D.H (1992) Productive Efficiency and Contract Management: Some Evidence from Public Transit Agencies. Public Finance Quarterly 20 (2) 195-215.

Hayes K and Chang S (1990) The Relative Efficiency of City Manager and Mayor-Council Forms of Government, Southern Economic Journal, 57(1), 167-177.

International City/County Management Association (2000). Municipal Year Book. Vol 67. ICMA: Washington.

Karlaftis M and McCarthy P (1997) Subsidy and Public Transit Performance: A Factor Analytic Approach. Transportation. 24, 253-270.

Karlaftis M and McCarthy P (1999) The Effect of Privatization on Public Transit Costs. Journal of Regulatory Economics 16(1), 27-43.

Morlok E and Viton P (1985) The Comparative Costs of Public and Private Providers of Mass Transit. In Lave, C. (ed) Urban Transit: The Private Challenge to Public Transportation, Chapter 10. Cambridge, MA: Ballinger Publishing Company.

Mueller D (1989). Public Choice II. Cambridge: University Press.

O'Leary, J (1993) Comparing Public and Private Bus Transit Services: A Study of the Los Angeles Foothill Transit Zone. RPPI Policy Study No. 163. Los Angeles: Reason Public Policy Institute.

Perry, James L. (1984). Organizational Forms and Transit Performance: A Research Review and Empirical Analysis. Research conducted for US Department of Transportation.

SAS Institute. 2001. Version. 8.2. SAS Inst., Cary, N.C.

Schork M. A. and D. R. Remington. 2000. Statistics with applications to the biological and health sciences, 3 rd edition. Prentice-Hall Inc. Upper Saddle River, New Jersey 07458.

Simpson A.U (1985) Implications of Efficiency Incentives on Use of Private Sector Contracting by the Public Transit Industry. In Lave, C. (ed) Urban Transit: The Private Challenge to Public Transportation, Chapter 13. Cambridge, MA: Ballinger Publishing Company.

Stokes BR (1979) The Need For and Use of Performance Indicators in Transit. Transit Journal1: 3-10.

Talley WK and Becker AJ (1982) A single measure for evaluating public transit systems. Transportation Quarterly 36(3): 423-431.

Teal, Roger F. (1988) Public Transit Service Contracting: A Status Report. Transportation Quarterly 42(2) 207-222.

Tomazinis AR (1975) Productivity, efficiency, and quality in urban transportation systems. Lexington, Mass: D.C. Heath and Company.

United States Census Bureau. (2002) United States Census 2000, Demographic Profiles (100\% Only). http://www.census.gov/Press-Release/www/2001/demoprofile.html 


\section{Appendix 1: List of Transit Agencies included in Sample}

\section{List of Transit Agencies and their organizational structure.}

\begin{tabular}{|c|c|}
\hline STATE & NAME \\
\hline AK & Municipality of Anchorage \\
\hline $\mathrm{AL}$ & City of Huntsville, Alaba \\
\hline AR & University of Arkansas \\
\hline $\mathrm{AZ}$ & Phoenix Publ Transit Dept \\
\hline $\mathrm{AZ}$ & City of Tucson \\
\hline $\mathrm{CA}$ & Golden Empire Transit Dst \\
\hline $\mathrm{CA}$ & Santa Cruz Metro Transit \\
\hline $\mathrm{CA}$ & Santa Monica Muni Bus \\
\hline $\mathrm{CA}$ & Torrance Transit System \\
\hline $\mathrm{CA}$ & Santa Clara Valley TA \\
\hline $\mathrm{CA}$ & Alameda-Contra Costa TD \\
\hline $\mathrm{CA}$ & Municipal Railway \\
\hline $\mathrm{CA}$ & GoldenGateBridge-Hwy\&TD \\
\hline $\mathrm{CA}$ & City of Santa Rosa \\
\hline $\mathrm{CA}$ & Sacramento RTD \\
\hline CA & Long Beach Publ Transp \\
\hline $\mathrm{CA}$ & San Diego Transit Corp \\
\hline $\mathrm{CA}$ & Fresno Area Express \\
\hline $\mathrm{CA}$ & OMNITRANS-Riverside \\
\hline $\mathrm{CA}$ & Culver City Municipal Bus \\
\hline $\mathrm{CA}$ & City of Gardena TD \\
\hline $\mathrm{CA}$ & Monterey-Salinas Transit \\
\hline $\mathrm{CA}$ & Central Contra Costa TA \\
\hline $\mathrm{CA}$ & SunLine Transit Agency \\
\hline $\mathrm{CA}$ & UNITRANS-Davis \\
\hline $\mathrm{CA}$ & Los Angeles County Metro \\
\hline $\mathrm{CA}$ & Ryder/ATE-LA \\
\hline $\mathrm{CO}$ & Colorado Springs Transit \\
\hline $\mathrm{CO}$ & Regional Transp District \\
\hline
\end{tabular}

\section{COMPANY}

Municipality of Anchorage - Public Transportation Department

City of Huntsville, Alabama Dept of Parking\&Public Transit

University of Arkansas, Fayetteville/Razorback Transit

City of Phoenix Public Transit Department

City of Tucson

Golden Empire Transit District

Santa Cruz Metropolitan Transit District

Santa Monica's Big Blue Bus

City of Torrance Transit System

Santa Clara Valley Trans. Authority

Alameda-Contra Costa Transit District

San Francisco Municipal Railway

Golden Gate Bridge, Highway and Transportation District

City of Santa Rosa

Sacramento Regional Transit District

Long Beach Public Transportation Company

San Diego Transit Corporation

Fresno Area Express

OMNITRANS

Culver City Municipal Bus Lines

City of Gardena Transportation Department

Monterey-Salinas Transit

Central Contra Costa Transit Authority

SunLine Transit Agency

UNITRANS University of California, Davis

Los Angeles County Metropolitan Transportation Authority

First Transit, Inc.

Colorado Springs Transit System

Regional Transportation District
STRUCTURE

GGPM

GGPM

SAPM

GGPM

GGPM

SAPM

SAPM

GGPM

GGPM

GGPM

SAPM

GGPM

SAPM

GGPM

SAPM

SAPM

SAPM

GGPM

SAPM

GGPM

GGPM

SAPM

SAPM

GGCM

SAPM

SAPM

SACM

SACM

SAPM 


\section{Section Appendix 1: List of Transit Agencies included in Sample}

\begin{tabular}{|c|c|c|c|}
\hline STATE & NAME & COMPANY & STRUCTURE \\
\hline $\mathrm{CO}$ & Pueblo Transit & Pueblo Transit & GGPM \\
\hline $\mathrm{CO}$ & City of Greeley-The Bus & City of Greeley-Transit Services & GGPM \\
\hline $\mathrm{CO}$ & City of Fort Collins & Transfort & GGPM \\
\hline $\mathrm{CT}$ & Hartford-CT Transit & Connecticut Transit-Hartford Division & SACM \\
\hline CT & Greater Bridgeport TD & Greater Bridgeport Transit Authority & SAPM \\
\hline CT & Housatonic Area Reg Trans & Housatonic Area Regional Transit & SAPM \\
\hline $\mathrm{CT}$ & New Haven-CT Transit & Connecticut Transit-New Haven Division & SACM \\
\hline $\mathrm{CT}$ & Stamford-CT Transit & Connecticut Transit-Stamford Division & SACM \\
\hline $\mathrm{CT}$ & Northeast Transp Comp & Northeast Transportation Company, Inc. & SAPM \\
\hline DC & Washington-Metro & Washington Metropolitan Area Transit Authority & SAPM \\
\hline $\mathrm{DE}$ & Delaware Transit Corporat & Delaware Transit Corporation & SAPM \\
\hline FL & Manatee Cnty Area Transit & Manatee County Area Transit & GGPM \\
\hline FL & Pinellas Suncoast Transit & Pinellas Suncoast Transit Authority & SAPM \\
\hline FL & Lee County Transit & Lee County Transit & GGPM \\
\hline FL & Broward Cnty Mass Transit & Broward County Mass Transit Division & GGPM \\
\hline FL & Lakeland Area Transit Dst & Lakeland Area Mass Transit District Citrus Connection & SAPM \\
\hline FL & County of Volusia-VOTRAN & County of Volusia d/b/a VOTRAN & GGPM \\
\hline FL & Miami-Dade Transit Agency & Miami-Dade Transit & GGPM \\
\hline FL & Central Florida Regnl TA & Central Florida Regional Transportation Authority & SAPM \\
\hline FL & City of Tallahassee & City of Tallahassee-TALTRAN & GGPM \\
\hline FL & Palm Tran & Palm Tran, Inc. & GGPM \\
\hline FL & Escambia Cnty Area Trans & Escambia County Area Transit & GGCM \\
\hline FL & Jacksonville Transp Auth & Jacksonville Transportation Authority & SAPM \\
\hline FL & Hillsborough Area RTA & Hillsborough Area Regional Transit Authority & SAPM \\
\hline FL & Sarasota County TA & Sarasota County Transportation Authority & GGPM \\
\hline FL & Space Coast Area Transit & Space Coast Area Transit & GGPM \\
\hline FL & Pasco County Public Trans & Pasco County Public Transportation (PCPT) & GGPM \\
\hline GA & Metro Atlanta RTA & Metropolitan Atlanta Rapid Transit Authority & SAPM \\
\hline GA & Augusta Richmond Co TD & Augusta Richmond Co. Transit Dept & GGPM \\
\hline GA & Columbus Transit System & Department of Transportation/METRA & GGPM \\
\hline GA & Chatham Area Transit Auth & Chatham Area Transit Authority & SAPM \\
\hline $\mathrm{HI}$ & City \& County of Honolulu & City and County of Honolulu Dept of Transportation Services & GGPM \\
\hline
\end{tabular}




\section{Section Appendix 1: List of Transit Agencies included in Sample}

STATE

NAME

IA

IA

IA

IA

ID

IL

IL

IL

IL

IL

IL

IL

IN

IN

IN

IN

IN

IN

IN

IN

KS

KS

KY

KY

KY

LA

LA

LA

LA

MA

MA

MD
Davenport Public Transit

Des Moines Metro Transit

Iowa City Transit

University of Iowa

Boise Urban Stages

Greater Peoria Transit

Rock Island County MTD

Rockford MTD

Champaign-Urbana MTD

Decatur Public Transit

Chicago Transit Authority

Pace, Suburban Bus Div

Metrop Evansville TS

Fort Wayne PTC

Gary Public Transportatio

Indianapolis Public Trans

Greater Lafayette PTC

South Bend Public Transp

Muncie Indiana Transit

Bloomington Public Transp

Topeka Metropolitan TA

Wichita Transit

TA Lexington-Fayette Cnty

Transit Auth - River City

TA - Northern Kentucky

Shreveport Area Transit

City of Monroe

RTA - Orleans \& Jefferson

Lafayette Transit System

Mass Bay Transp Auth

Worcester Regional TA

MTA-Maryland DOT
COMPANY

STRUCTURE

Davenport Public Transit

GGCM

Des Moines Metropolitan Transit Authority

SAPM

Iowa City Transit

GGPM

University of Iowa, CAMBUS

SAPM

Boise Urban Stages

GGPM

Greater Peoria Mass Transit District

SAPM

Rock Island County Metropolitan Mass Transit District

SAPM

Rockford Mass Transit District

SAPM

Champaign-Urbana Mass Transit District

SAPM

Decatur Public Transit System

GGCM

Chicago Transit Authority

SAPM

Pace, Suburban Bus Division

SAPM

Metropolitan Evansville Transit System

GGPM

Fort Wayne Public Transportation Corporation

SAPM

Gary Public Transportation Corporation

SAPM

Indianapolis Public Transportation Corporation

GGPM

Greater Lafayette Public Transportation Corporation

SAPM

South Bend Public Transportation Corporation

SAPM

Muncie Indiana Transit System

SAPM

Bloomington Public Transportation Corporation

SACM

Topeka Metropolitan Transit Authority

SAPM

Wichita Transit

GGPM

Transit Authority Lexington- Fayette Urban County Government

SAPM

Transit Authority of River City

GGPM

Transit Authority of Northern Kentucky

SACM

Shreveport Area Transit System

GGPM

City of Monroe Transit System

GGPM

Regional Transit Authority of Orleans and Jefferson

GGCM

Lafayette Transit System LTS

GGPM

Massachusetts Bay Transportation Authority

SAPM

Worcester Regional Transit Authority

SAPM

Mass Transit Administration, Maryland Dept. of Transportation

SAPM 


\section{Section Appendix 1: List of Transit Agencies included in Sample}

\begin{tabular}{|c|c|c|c|}
\hline STATE & NAME & COMPANY & STRUCTURE \\
\hline MD & Annapolis Parking/Trans & Annapolis Department of Transportation & GGPM \\
\hline MD & Montgomery Cnty Ride-On & Ride-On Montgomery County Government & GGPM \\
\hline ME & Greater Portland Transit & Greater Portland Transit District & GGPM \\
\hline MI & Battle Creek Transit & Battle Creek Transit & GGPM \\
\hline MI & Suburban Mobility Auth RT & Suburban Mobility Authority for Regional Transportation & SACM \\
\hline MI & Mass Transportation Auth & Mass Transportation Authority & SAPM \\
\hline MI & Interurban Transit & Interurban Transit Partnership & SAPM \\
\hline MI & Kalamazoo Metro Trans Sys & Kalamazoo Metro Transit System & GGPM \\
\hline MI & Capital Area Transp Auth & Capital Area Transportation Authority & SAPM \\
\hline MI & Muskegon Area Transit Sys & Muskegon Area Transit System & GGPM \\
\hline MI & Ann Arbor Transp Auth & Ann Arbor Transportation Authority & SAPM \\
\hline MI & City of Detroit DOT & City of Detroit Department of Transportation & GGPM \\
\hline MI & University of Michigan & University of Michigan Parking and Transportation Services & SAPM \\
\hline $\mathrm{MN}$ & Metro Transit & Metro Transit & SAPM \\
\hline $\mathrm{MN}$ & St Cloud Metropln Transit & St. Cloud Metropolitan Transit Commission & SAPM \\
\hline $\mathrm{MO}$ & Springfield Utilities & City Utilities of Springfield Transit Services & SAPM \\
\hline MO & Kansas City Area TA & Kansas City Area Transportation Authority & SACM \\
\hline $\mathrm{MO}$ & Bi-State Development & Bi-State Development Agency & SAPM \\
\hline MS & Mississippi Coast TA & Mississippi Coast Transportation Authority & SAPM \\
\hline MT & Missoula Urban Transport & Missoula Urban Transportation District & SAPM \\
\hline NC & Asheville Transit Auth & Asheville Transit Authority & SACM \\
\hline NC & Wilmington Transit Auth & Wilmington Transit Authority & SACM \\
\hline NC & Capital Area Transit & Capital Area Transit & SACM \\
\hline NC & Fayettville Area System & Fayetteville Area System of Transit & GGPM \\
\hline NC & High Point Transit & High Point Transit & GGPM \\
\hline NC & Chapel Hill Transit & Chapel Hill Transit & GGPM \\
\hline NC & Durham Area Transit & Durham Area Transit Authority & GGPM \\
\hline NE & Omaha Transit Authority & Transit Authority of Omaha & SAPM \\
\hline $\mathrm{NH}$ & Manchester Transit Auth & Manchester Transit Authority & SAPM \\
\hline NJ & New Jersey Transit & New Jersey Transit Corporation (Consolidated) & SAPM \\
\hline NJ & Academy Lines & Academy Lines, Inc. & SACM \\
\hline NJ & Hudson Transit Lines & Hudson Transit Lines, Inc. & SACM \\
\hline
\end{tabular}




\section{Section Appendix 1: List of Transit Agencies included in Sample}

STATE

NAME

NJ

Suburban Transit Corp

$\mathrm{NJ}$

NV

NY

NY

NY

NY

NY

NY

NY

NY

NY

NY

NY

$\mathrm{OH}$

$\mathrm{OH}$

$\mathrm{OH}$

$\mathrm{OH}$

$\mathrm{OH}$

$\mathrm{OH}$

$\mathrm{OH}$

$\mathrm{OH}$

$\mathrm{OH}$

$\mathrm{OH}$

OK

OR

OR

OR

PA

PA

PA

PA
COMPANY

STRUCTURE

Suburban Transit Corporation

SACM

New Jersey Transit Corporation (45)

SACM

ATC/VanCom

SACM

Broome County Department of Public Transportation

GGPM

Niagara Frontier Transit Metro System, Inc.

GGPM

Metropolitan Suburban Bus Authority dba MTA Long Island Bus

GGPM

New York City Transit

SAPM

Dutchess County Division of Mass Transportation

SACM

CNY Centro, Inc.

GGPM

Utica Transit Authority

SAPM

Liberty Lines Transit, Inc.

SACM

Regional Transit Service, Inc. \& Lift Line, Inc.

SAPM

Liberty Lines Express, Inc.

SACM

GTJC

SACM

Metro Regional Transit Authority

SAPM

Stark Area Regional Transit Authority

SAPM

Southwest Ohio Regional Transit Authority

SAPM

The Greater Cleveland Regional Transit Authority

SAPM

Central Ohio Transit Authority

SACM

Miami Valley Regional Transit Authority

SAPM

Springfield City Area Transit

GGCM

Toledo Area Regional Transit Authority

SAPM

Western Reserve Transit Authority

SAPM

LAKETRAN

GGPM

Central Oklahoma Transit \& Parking Authority

GGPM

Lane Transit District $\quad$ SAPM

Tri-County Metropolitan Transportation Dist. of Oregon SAPM

Rogue Valley Transit District

SAPM

Lehigh and Northampton Transportation Authority

SAPM

Altoona Metro Transit

SAPM

Cambria County Transit Authority

GGPM

Luzerne County Transportation Authority 


\section{Section Appendix 1: List of Transit Agencies included in Sample}

\begin{tabular}{|c|c|c|c|}
\hline STATE & NAME & COMPANY & STRUCTURE \\
\hline $\mathrm{PA}$ & Red Rose Transit Auth & Red Rose Transit Authority & SAPM \\
\hline $\mathrm{PA}$ & SEPTA & Southeastern Pennsylvania Transportation Authority & GGCM \\
\hline $\mathrm{PA}$ & Port Authority Allegheny & Port Authority of Allegheny County 345 Sixth Avenue & GGPM \\
\hline $\mathrm{PA}$ & Lackawanna Transit Sys & County of Lackawanna Transit System & SAPM \\
\hline PA & Williamsport Bureau Trans & Williamsport Bureau of Transportation & GGPM \\
\hline $\mathrm{PA}$ & Centre Area Transp Auth & Centre Area Transportation Authority & SAPM \\
\hline RI & RI Public Transit Auth & Rhode Island Public Transit Authority & SAPM \\
\hline SC & Greenville Transit Auth & Greenville Transit Authority & GGCM \\
\hline SC & Pee Dee RTA & Pee Dee Regional Transportation Authority & SAPM \\
\hline SC & South Carolina Electric \& & South Carolina Electric \& Gas Company-Columbia & SACM \\
\hline SC & Coastal Rapid Public TA & CRPTA - Waccamaw Regional Transportation Authority & SAPM \\
\hline SD & Sioux Falls Transit & Sioux Falls Transit & GGCM \\
\hline $\mathrm{TN}$ & Chattanooga Area RTA & Chattanooga Area Regional Transportation Authority & GGPM \\
\hline $\mathrm{TN}$ & Metropolitan Transit Auth & Metropolitan Transit Authority & SAPM \\
\hline $\mathrm{TX}$ & Amarillo City Transit & Amarillo City Transit P O Box 1971 & GGPM \\
\hline TX & El Paso Mass Transit & Mass Transit Department-City of El Paso & GGPM \\
\hline $\mathrm{TX}$ & Fort Worth Transp Auth & Fort Worth Transportation Authority & SAPM \\
\hline $\mathrm{TX}$ & MetroTransAuth HarrisCnty & Metropolitan Transit Authority of Harris County, Texas & SAPM \\
\hline $\mathrm{TX}$ & Laredo Municipal Transit & Laredo Metro, Inc. & SACM \\
\hline $\mathrm{TX}$ & City Transit Mgmt Comp & City Transit Management Company,Inc & SACM \\
\hline $\mathrm{TX}$ & Waco Transit System & Waco Transit System, Inc. & SACM \\
\hline TX & Beaumont Transit System & Beaumont Transit System & SACM \\
\hline TX & Capital Metro Transp Auth & Capital Metropolitan Transportation Authority & SACM \\
\hline $\mathrm{TX}$ & Corpus Christi Regionl TA & Corpus Christi Regional Transportation Authority & SAPM \\
\hline $\mathrm{TX}$ & Dallas Area RTA & Dallas Area Rapid Transit Authority & SAPM \\
\hline $\mathrm{TX}$ & First Transit, Inc & First Transit, Inc. & SACM \\
\hline $\mathrm{TX}$ & Ryder/ATE & First transit,inc & GGPM \\
\hline UT & Utah Transit Authority & Utah Transit Authority P. O. Box 30810 & SAPM \\
\hline VA & Greater Richmond Transit & Greater Richmond Transit Company & GGCM \\
\hline VA & Greater Roanoke Transit & Greater Roanoke Transit Company & GGCM \\
\hline VA & Charlottesville Transit & Charlottesville Transit Service & GGPM \\
\hline VA & City of Alexandria & City of Alexandria, Alexandria Transit Company & GGPM \\
\hline
\end{tabular}




\section{Section Appendix 1: List of Transit Agencies included in Sample}

STATE NAME

WA King County DOT

WA Pierce Transit

WA Everett Transit

WA Ben Franklin Transit

WA Intercity Transit

WA Kitsap Transit

WA Clark County Public Trans

WA Snohomish Cnty Transp BAC

WI Green Bay Transit

WI Kenosha Transit

WI LaCrosse Municipal Trans

WI Madison Metro Transit

WI Belle Urban System-Racine

WI Milwaukee Cnty Trans Sys

WI Oshkosh Transit System

WI Sheboygan Transit System

WI Waukesha Transit Comm

WI Janesville Transit System

WV Kanawha Valley RTA

WV Tri-State Transit Auth

WV Ohio Valley RTA

WY City of Cheyenne Transit
COMPANY

STRUCTURE

King County Department of Transportation - Metro Transit Div.

GGPM

Pierce County Public Benefit Benefit Authority

SAPM

Everett Transit

GGPM

Ben Franklin Transit

SAPM

Intercity Transit

SAPM

Kitsap Transit

SACM

Clark County Public Transportation Benefit Area Authority

SAPM

Snohomish County Transportation Benefit Area Corporation

GGPM

Green Bay Metro

GGPM

Kenosha Transit

GGPM

LaCrosse Municipal Transit Utility

GGPM

Madison Metro Transit

GGPM

Belle Urban System-Racine

GGPM

Milwaukee County Transit System

GGCM

Oshkosh Transit System

GGPM

Sheboygan Transit System

GGPM

Waukesha Transit Commission

SACM

Janesville Transit System

GGPM

Kanawha Valley Regional Transportation Authority

SAPM

The Tri-State Transit Authority

SAPM

Ohio Valley Regional Transportation Authority

SAPM

The City of Cheyenne Transit Program

GGPM

Source: Information obtained from transit official during interview to determine type of structure of transit agencies. The threequestion survey is on page 47 of this study. Agencies randomly selected. 


\section{Appendix 2: Transportation Structure and Performance Questionnaire}

Florida A\&M University, College of Arts \& Sciences in cooperation with the Florida Department of Transportation is conducting a study to show the correlation, if any, that exists between management strategies and performance of transportation agencies. This study is being performed on a nation wide basis. As part of the study your participation is requested. Please complete the attached questionnaire which inquires mainly into your management style, habits, and strategies.

Thank you for your cooperation and participation.

\section{QUESTIONNAIRE}

1. How long have you been a manager with this or any other transit agency? (number of years)

2. With which of the following levels of government and its relevant agencies does YOUR agency interact with most often?

$\square$ Local government

$\square$ State government

- Federal government

$\square$ Non-governmental organizations

3. How would you rate the quality of interaction with these governmental agencies/organizations?

$\square$ Excellent

$\square$ Acceptable but could be improved

$\square$ Poor

4. What local, state, or federal guidelines most FACILITATE the efficient and effective provision of transit services?

$\square$ Environmental

a Fiscal/Financial

$\square$ Land use statutes

$\square$ Economic

a Other 
5. What local, state, or federal guidelines most HINDER the efficient and effective provision of transit services?

- Environmental

a Fiscal/Financial

$\square$ Land use statutes

$\square$ Economic

Other

6. Which of the following contributes to less than optimal transit service delivery?

$\square$ Decision rules do not allow for enough creativity and individual judgment.

$\square$ Rules are too broad and do not give individual agencies enough guidance for independent action.

$\square$ Decision rules are always changing and do not give enough time for observable results.

- Transit agencies are budget recipients of last resort and therefore experiences minimal efficiency in operations and service delivery.

7. In your opinion, the decision rules indicated above could be

$\square$ Significantly changed

$\square$ Continued with some reform

$\square$ Discontinued

$\square$ Not sure

8. Does your agency subscribe to in-house or external training or continuing education training programs for managers, supervisors, staff and operators?

Frequently

$\square$ Infrequently

a Never

9. Has your transit agency contributed to or actively supported the development of nearby community-oriented facilities such as: daycare centers, health care facilities, job placement centers, or police substations provided?

$\square$ Yes

口 No 
If you answered "YES" to question 9, please answer questions 10 and 11, otherwise go to question 12. If you answered "yes" above, which facilities are commonly found near your transit nodes? (You may select more than one.)

$\square$ day-care centers

bealth care facilities

$\square$ police substations

$\square$ job placement centers

$\square$ other

11. Have you noticed a more positive attitude by facility users toward the transit agency?

$\square$ Yes

$\square$ No

$\square$ Not sure

12. Is your transit agency

Part of a municipal government

$\square$ An independent authority

$\square$ Other

13. Does your transit agency have its own independent taxing authority?

$\begin{array}{ll}\square & \text { Yes } \\ \square & \text { No }\end{array}$

14. Are the top-level managers in your agency employees of

$\square$ A municipal government

$\square$ A private transit management company

$\square$ Another entity (please specify)

Name:

Email Address:

Title:

Agency:

Date Questionnaire Completed: 